
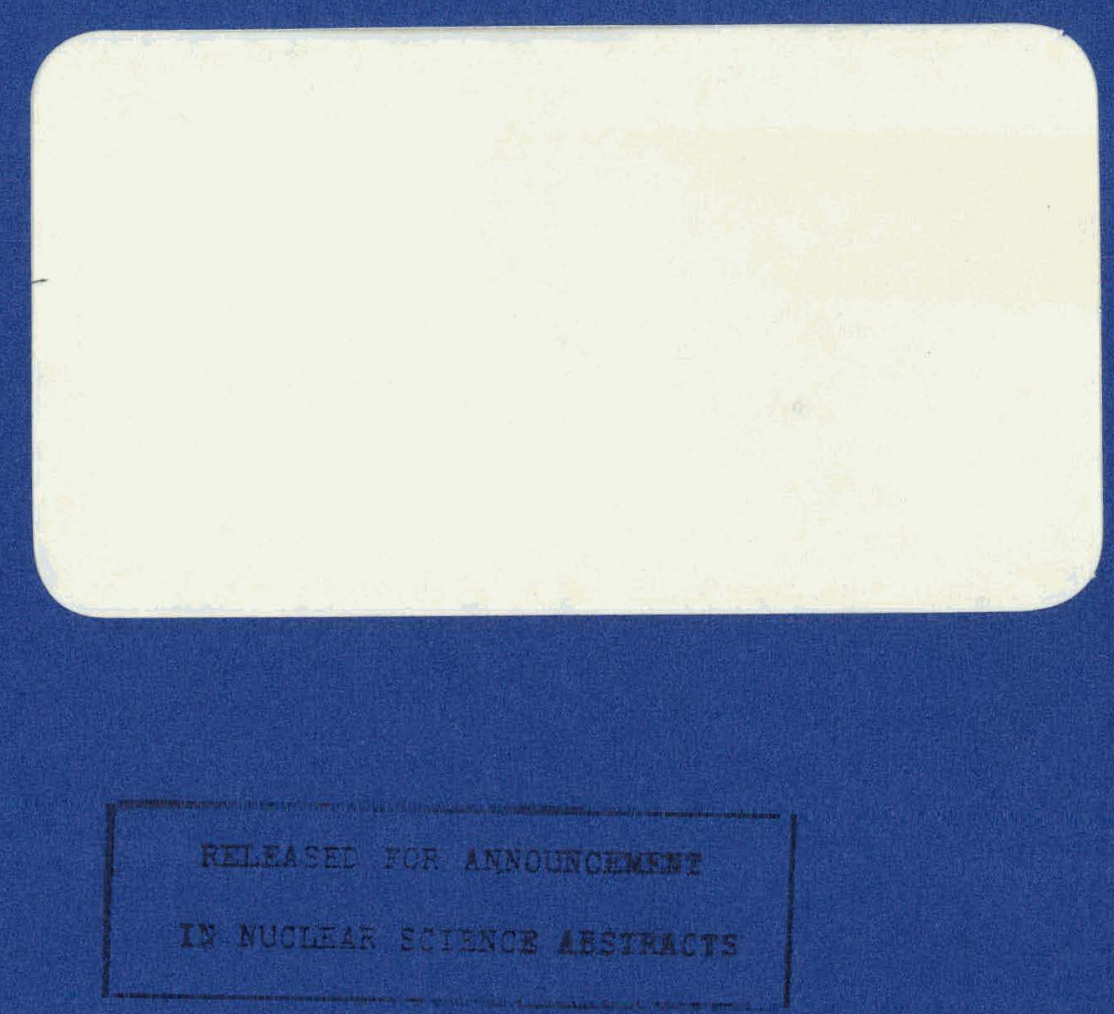

Westinghouse Atomic Power Divisions

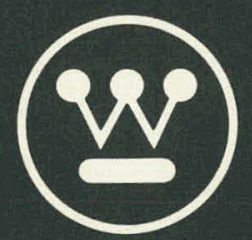




\section{DISCLAIMER}

This report was prepared as an account of work sponsored by an agency of the United States Government. Neither the United States Government nor any agency Thereof, nor any of their employees, makes any warranty, express or implied, or assumes any legal liability or responsibility for the accuracy, completeness, or usefulness of any information, apparatus, product, or process disclosed, or represents that its use would not infringe privately owned rights. Reference herein to any specific commercial product, process, or service by trade name, trademark, manufacturer, or otherwise does not necessarily constitute or imply its endorsement, recommendation, or favoring by the United States Government or any agency thereof. The views and opinions of authors expressed herein do not necessarily state or reflect those of the United States Government or any agency thereof. 


\section{DISCLAIMER}

Portions of this document may be illegible in electronic image products. Images are produced from the best available original document. 


\title{
FISSION PRODUCTS FROM FUEL DEFECT TEST AT SAXTON
}

\section{LEGAL NOTICE}

This report was prepared as an account of Covernment sponsored work. Netther the United States, nor the Commission, nor any person acting on behalf of the Commission:

A. Makes any warranty or representation, expressed or implied, with respect to the accuracy, completeness, or usefulness of the information contalned in thls report, or that the use of any Information, apparatus, method, or process disclosed in this report may not infringe privalely owned rights; or

B. Assumes any liabllities with respect to the use of, or for damages resulting from the of any information, apparatus, method, or proceds dlaclosed in thls report.

As used in the above. "person acting on behalf of the Commlsalon" includes any em. ployee or contractor of the Commission, or employee of such contractor, to the extent that such employee or contractor of the Commiasion, or employee of such contractor prepares, disseminates, or provides access to, any Information pursuant to hls employment or contract with the Commission, or hls employment with such contractor.

\section{by}

W. D. Fletcher and

L.: F.'Picone.

Chemistry Section

April 1966

Prepared for the U. S. Atomic Energy Commission Under New York Operations Office Contract AT(30-1)-3269

(Subtask LRD-4n?)

\author{
WESTINGHOUSE ELECTRIC CORPORATION \\ Atomic Power Division \\ Box 355 \\ Pittsburgh, Pennsylvania 15230
}




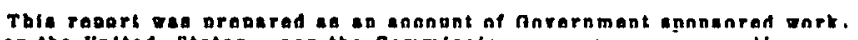

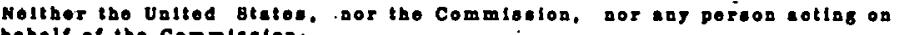
bohelf of tho Commiation:

A. Mekes anj werrenty or reprocentation, exprosuod or impllod, witb reapoot to tho cootreoj, complotonose, or usofulnoes of tbo toformetion oontelned in thle roport. or that the veo of eay latormellen, epperates.

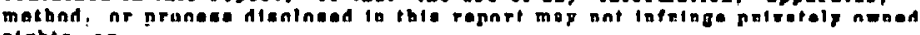
righte; or

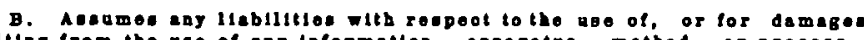
readilag from the uso of eng loformatlon, epperatre. mothod, or prooose dicolosed in thie roport.

Ad aced to the cbore, "Peraon coting of bobell of the comminelon" inoludos any omplojec or oontraotor of tho commietion, or emplojec of ouob

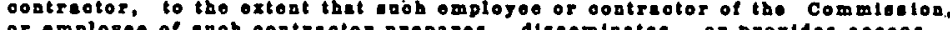

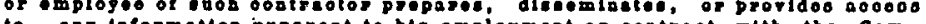
to. eng information purount to ble omployment or oontreot with the Com-

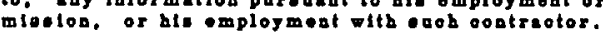


USAEC, New York Operations Office, 376 Hudson Street, New York 14,

USAEC, Assistant General Counsel for Patents; Germantown, Maryland

General Electric Atomlc Power Equipment Dept., 2151 South First St.,

The Babcock \& Wilcox Co., Atomic Energy Division, 1201 Kemper St., 
Page Number

List of Figures

iv

List of Tables

$\mathrm{V}$

Abstract

vi

Summary

vii

I. Introduction 1

II. Experimental Procedures

A. The Fuel Rod and Defect. 3

B. Placement of Defect Rod in Reactor 3

III. Reactor Operations and Water Chemistry 14

IV. Sample Analysis and Test Results 18

V. Mathematical Analysis of Fission Product Data 22

VI. Analysis of Data Collected During Defect Test. . 30

VII. Discussion of. Results . . . . 37

VIII. Conclusions $4 I$

Appendices $\quad 42$

Al. Radiochemical Analysis of Solutions. 43

A2. Separation and Analysic of Fiodion Gases frum
Solution

Bibliography $\quad \ldots \quad 46$ 


\section{LIST OF FIGURES}

Figure No.

Title

Page No.

I ... Photograph of $15 \mathrm{mil}$ Diameter Defect in Zircaloy Clad Rod Following Exposure in Saxton Reactor

Gamma Scan of Fuel Rod from Saxton Core Center Position

After Irradiation

3. Intentional Defect in Zircaloy Clad Rod No. 321

4. Disassembled Fuel Bearing Portion of Saxton Special Removable $3 \times 3$ Tuel Assembly.

5. Orientation of the Saxton Special Removable In-Pile 3x3 Defect Test Assembly

6 End View and Arrangement of $9 \times 9$ Fuel Assembly No. 503-10-1

7 Plan View of the Saxton Core Illustrating the Saxton Special As semblies

8. Saxton Reactor Operations and Coolant Chemistry

10: Removal of Fission Products from Saxton Coolant by 


\section{LIST OF TABLES}

Table No.

Title

Page No.

1 Dimensions and Characteristics of Saxton Defected Fuel Rod

$2:$ Summary of the Special Removable In-Pile 3x3 Defect Test Assembly

3 Fission Product Iodine Activity in Saxton CoolantNo Purification

4 . Fission Product Activity in Saxton Coolant-With Purification

Fission Product Decay Schemes

6 Summary of Equations Used for Defect Analysis

Constants Used In Fission Product Analysis 
ABSTRACT

An intentional fuel cladding defect was placed in the Sexton Nuclear plant and the reactor operated at and near full power during a calender period of 57 days. Primary coolant samples were analyzed for fission products and escape rate coefficients for the iodine and fission gases were estimated therefrom. The calculated $\nu$ 's for iodine are $2 \times 10^{-9}$ $\sec ^{-1}, 8 \times 10^{-9} \sec ^{-1}$, and $14 \times 10^{-9} \sec ^{-1}$, for $I^{131}, I^{133}$, and $I^{135}$ respectively. Fission gas $\mathrm{Xe}^{133}$ and $\mathrm{Kr}^{88}$ indicated average $v^{\prime}$ s of about $25 \times 10^{-9}$.

vi 
1. An experimental $3 \times 3$ fuel rod assembly, with one rod intentionally defected by drilling a $15 \mathrm{mil}$ diameter hole through the cladding, was operated in the Saxton nuclear reactor for 57 days at between 10 and 23.5 MWt, accumulating 1230 MWD irradiation.

2. Coolant samples collected from the primary system were analyzed for fission product iodines and gases with the objective of defining the magnitude of escape rate coefficients.

3. Escape rate coefficients calculated from the coolant activities were as follows:

$$
\begin{array}{ll}
\text { I-131 } & 2 \times 10^{-9} \mathrm{sec}^{-1} \\
\text { I-133 } & 8 \times 10^{-9} \mathrm{sec}^{-1} \\
\text { I-135 } & 14 \times 10^{-9} \mathrm{sec}^{-1} \\
\text { Xe-133 } & 20 \times 10^{-9} \mathrm{sec}^{-1} \\
\text { Kr-88 } & 30 \times 10^{-9} \mathrm{sec}^{-1}
\end{array}
$$

The values of these coefficients is less by a factor of up to 6 for the iodines and about half that for the gases used in some design calculations heretofore.

4. Computations of nuclide atom ratios in the coolant from data collected during this test are, at best, a qualitative indication that the source of fission products was a clad defect. 
5. Operation of the mixed-bed, K/Borate, purification demineralizer during the test showed that fission product iodines and tramp sodium were removed with high efficiency. Fission product cesium, as expected, was not removed by the potassium form exchanger to any significant extent. 


\section{I. : INTRODUCTION}

Within the overall scope of the Large Closed Cycle Reactor Research and Development program at WAPD for the design and evaluation of new concepts in reactor technology, it was desirous to operate a reactor with a known clad defect in one or more fuel-tubes in a chemical shim environment. This would present an opportunity to monitor the metallurgical aspects of a defect in such an operating reactor, was well as, to measure the quantity of fission products that would be enitted to the reactor coolant. It is the latter of these programs to which this report is devoted. Other aspects of the "defect test", are reported elsewhere. $L 1$

The test of fission products release from the defect element, in general, consisted of drilling through the clad of a fuel tube, giving a 0.015 inch diameter hole, which may be conservatively compared with a weld defect. In order to obtain the highest release rate of fission products from the fuel tube, the defect was located near the middle of the rod and the rod was placed in the core center of the Saxton reactor. Thus the defect was located at the point of highest neutron flux in the reactor core. With the defect located therein, the reactor was operated for 57 days accumulating a total of approximately $1230 \mathrm{MWD}$ at between 10 and 23.5 MWt. The defected rod operated at a peak power of $13.5 \mathrm{kw} / \mathrm{ft}$ and accumulated $\approx 3000 \mathrm{MWD} / \mathrm{MTU}$ peak with a peak to average ratio of 1.387 . During this time, coolant samples were collected and analyzed for fission products, such as $\mathrm{I}^{131}, \mathrm{I}^{133}, \mathrm{1}^{135}$, $\mathrm{Xe}^{133}$, etc., at near steady-state operating conditions, from which calculations of escape rates f'rom the defect can be ascertained. 
In the following Sections, detailed descriptions of the test procedure are given followed by a presentation of coolant analyses and interpretation of the test results. 
II.: Experimental Procedures

\section{A. The Fuel Rod and Defect}

A new fuel rod, having standard dimensions for the Saxton reactor, was fabricated for the defect test. Characteristics of this rod were as given in Table 1. The fuel pellets were clad with Zjicciloy-4, furnace-preoxidized on the exterior surfaces prior to drilling the defect. The defect was machine-drilled to a diameter of 0.015 inches and was located axially at the point of highest power and neutron flux. A photograph of the defected rod is presented in Figure 1. That the defect was located at the point of highest flux is illustrated in Figure 2, which shows a typical gamma-scan profile for a Saxton rod removed after operation in the same core-center positions as the defected rod.

To better illustrate the clad defect, Figure. 3 shows a cross section of the rod obtained after the test during post-irradiation examination of the fuel rod. The defect is clearly seen to penetrate the clad, thus exposing the fuel to tho cutcrior eirvirument.

\section{B. Placement of Defect Rod in Reactor}

Fnllowing fabrication and drillng the defect, hod 321 was positioned in a $3 \times 3$ subascembly, number 503-4-24. This subassembly contained fuel rols enclosed in a square array within a perforated can as shown disassembled in Figure 4. The subassembly contained four removable and five stationary rods, with design features as summarizcd in Table 2, and arrarged in the $3 \times 3$ as shown in Figure 5. 
Dimensions and Characteristics of the Saxton Defect Fuel Tube

Code Number

321

Materials of Construction

Clad

Zirc-4

Fnd Plugs

Zirc-4

Fuel

$\mathrm{UO}_{2}$

$\mathrm{U}^{235}$ Enrichment, percent

6.10

Physical Dimensions

Fuel Tube

Length (including end-plugs), inches

41.44

Outside diameter, inches, nominal

0.391

Clad thickness, inches, nominal

0.024

Inside diameter, inches, nominal

0.344

Fuel Pellets

Outside diameter, inches, nominal

0.337

Length, inches, nominat

0.732

Total number of pellets

48

Total fucl length, inches

34.9

Pellet to clad diametrical gap, inches, nominal

0.0065

Total Weight $\mathrm{UO}_{2}$, grams/\% Theurelicul Densily

$5.8 / 95$

Total Weight $\mathrm{U}^{235}$, grams

28

Peak Power (in Saxton core center, $Q=23.5 \mathrm{MWt}$ ), $\mathrm{kw} / \mathrm{ft}$

13.5

Peak lu Average Power in Rod,

1.387

Trel Burnup (at eid of lest), MWD/MTU, in defect rod

$\approx 3000$ peak

Defect Diameter in $\mathrm{Clad}$, inches

0.015

Defect Location (above tip of bottom end-plug), inches

17.25 


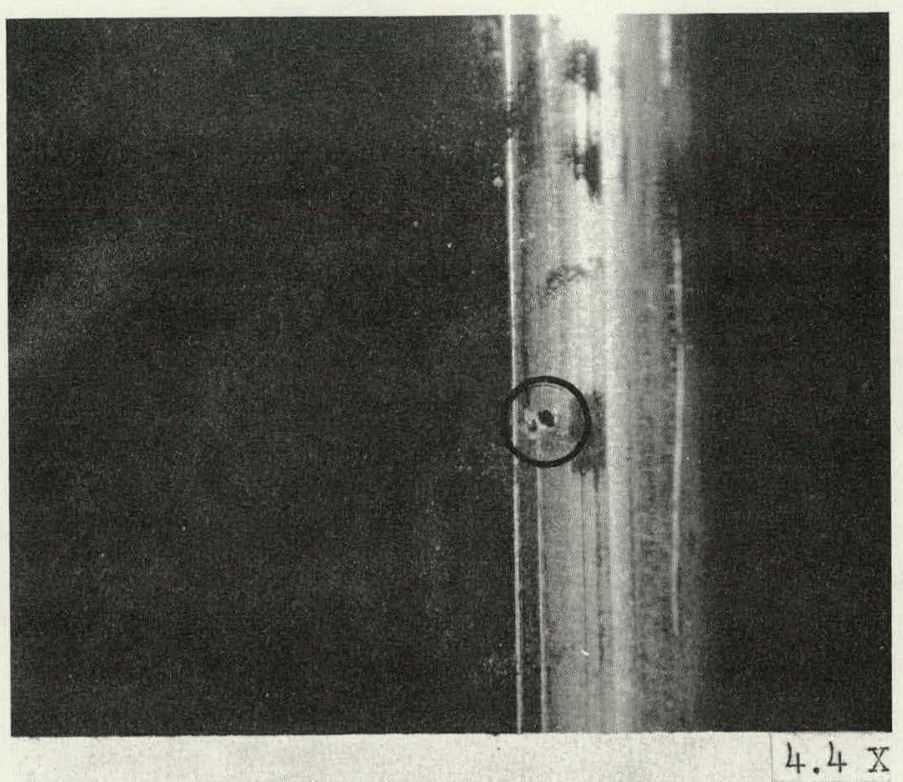

Photograph of 15 Mil Diameter Defect In Zircaloy Clad Rod Following 56

E. F. P. Days Exposure In A Borated PWR Environment

Figure 1 
Figure 2

Gamma Scan - Fuel Rod \#14

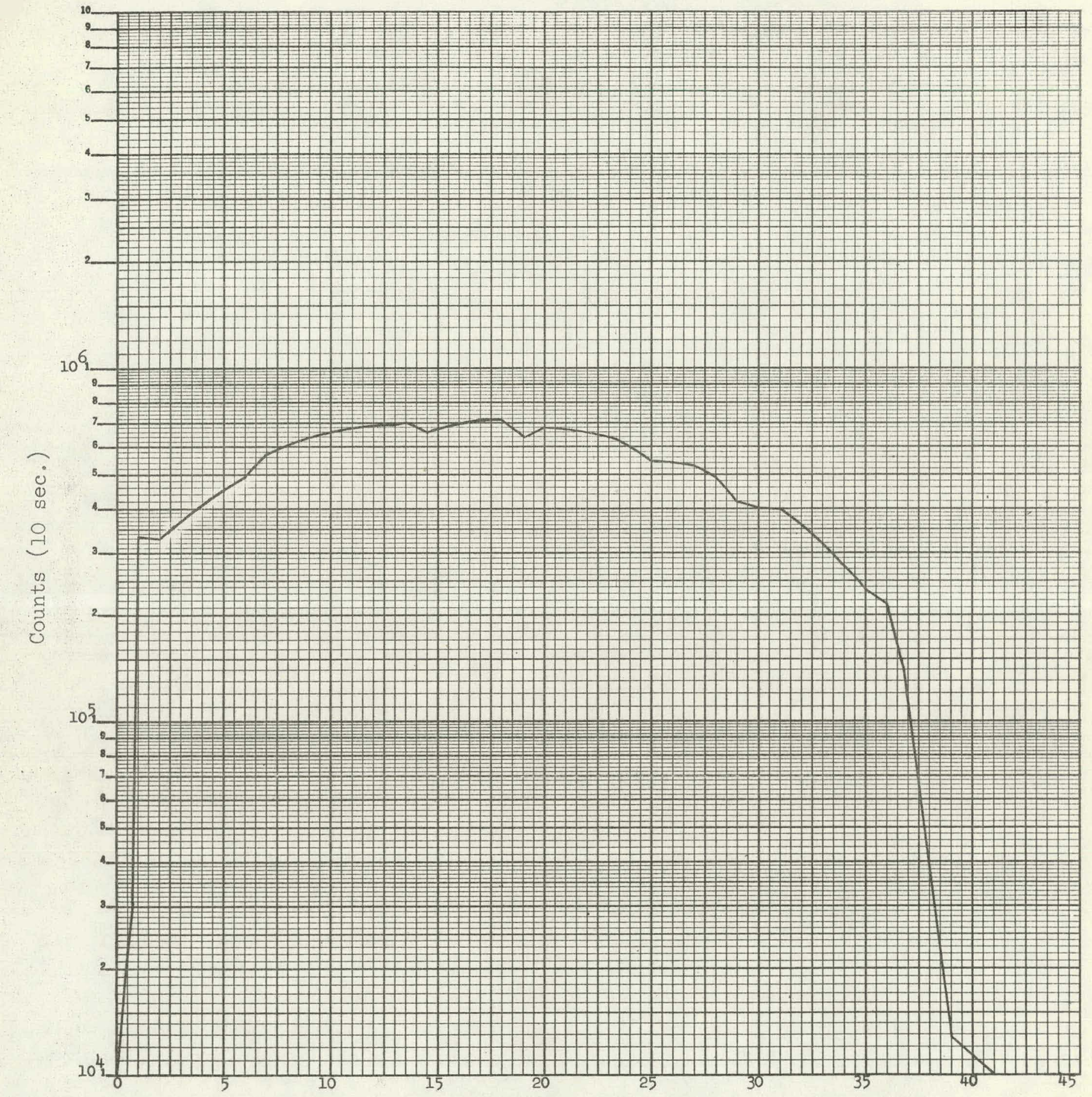

Inches Prom Bottom of Rod

$$
\begin{gathered}
\text { Figure } 2 \\
\text { Gamma Scan of Fuel Rod } \\
\text { from Saxton Core Center Position } \\
\text { After Trradiation }
\end{gathered}
$$




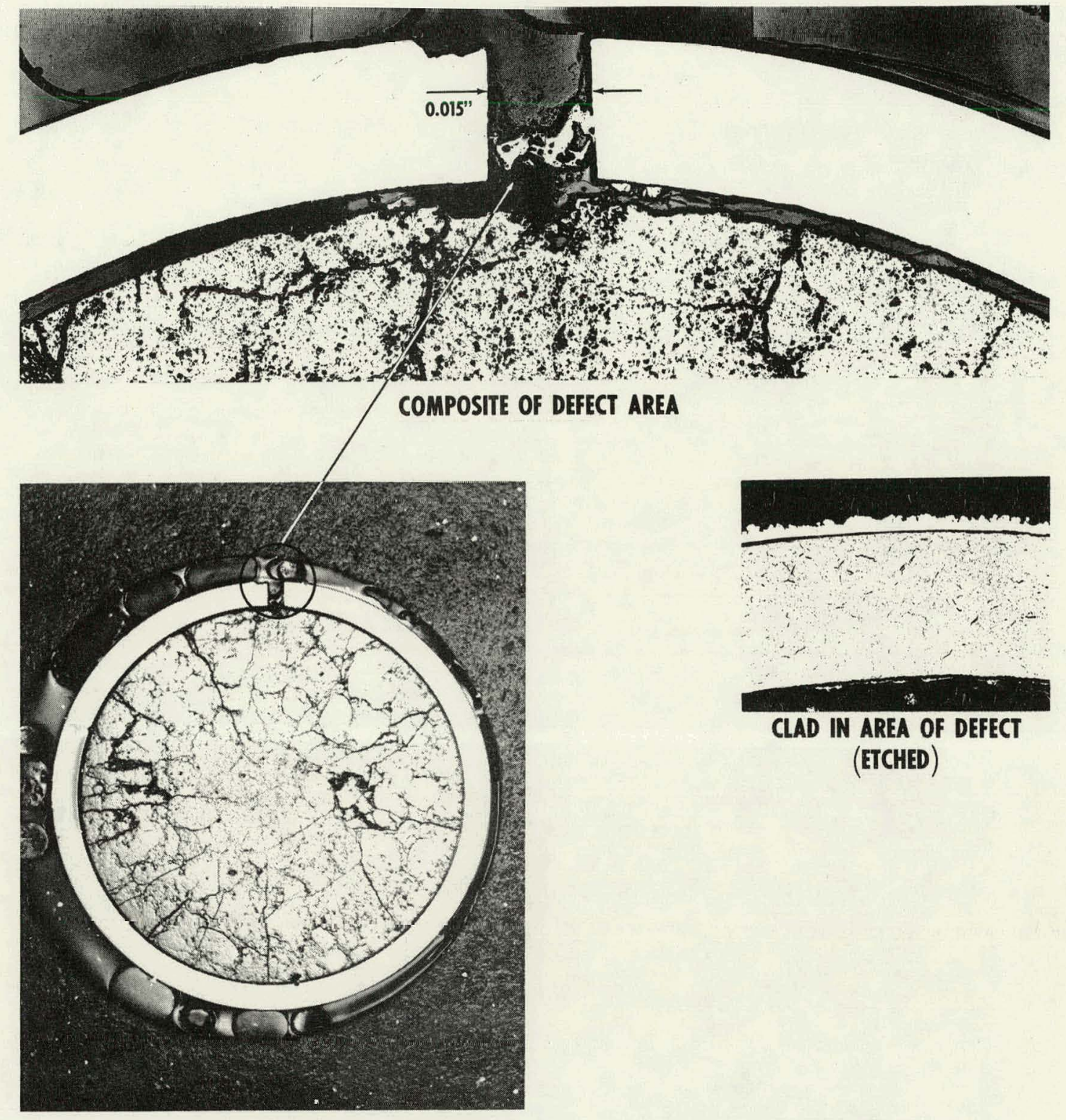

INTENTIONAL DEFECT IN ZIRCALOY CLAD ROD NO.321

Figure 3 


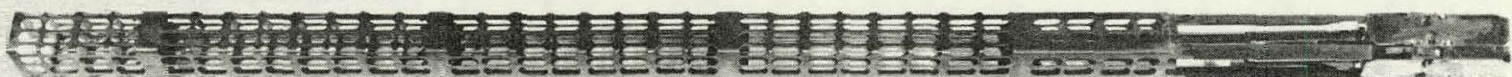 80.8

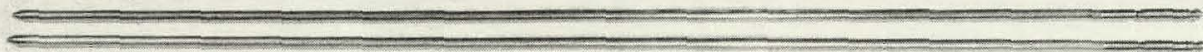

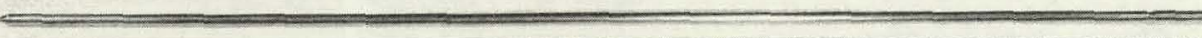

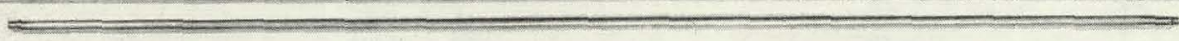

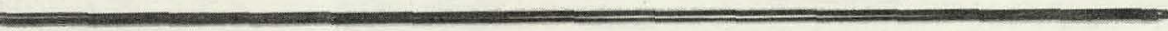

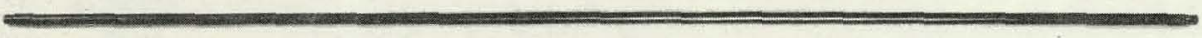

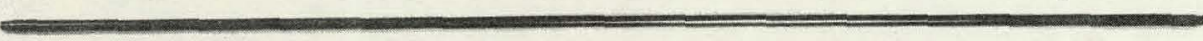

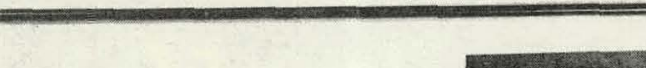

DISASSEMBLED FUEL BEARING PORTION OF SAXTON SPECIAL REMOVABLE $3 \times 3$ FUEL ASSEMBLY.

Figure 4 


\section{TABLE 2}

Sumary cf the Sexton Special Removable In-P1le $3 \times 3$ Defect Test Assembly

\begin{tabular}{|c|c|c|c|c|c|c|c|c|c|}
\hline $\begin{array}{l}\text { Saxton } \\
\text { Core } \\
\text { Position }\end{array}$ & $\begin{array}{l}\text { Fuel } \\
\text { Rod } \\
\text { Number }\end{array}$ & $\begin{array}{l}\text { Cladiding } \\
\text { Material }\end{array}$ & $\begin{array}{l}\text { Fuel Rod } \\
\text { Type }\end{array}$ & $\begin{array}{l}\text { Number of } \\
\text { Fuel } \\
\text { Pellets }\end{array}$ & $\begin{array}{l}\text { Enrichment } \\
\left(\begin{array}{ll}\% & U_{235}\end{array}\right)\end{array}$ & $\begin{array}{l}\mathrm{UO}_{2} \\
\text { (g) }\end{array}$ & $\begin{array}{l}\mathrm{U}_{235} \\
\text { (g) }\end{array}$ & Defected & $\begin{array}{l}\text { Previous } \\
\text { Exposure }\end{array}$ \\
\hline N-1 & 101 & Zircaloy -4 & Removable & 48 & 6.10 & 528 & 26 & No & Yes (2) \\
\hline$N-I$ & 102 & Zircaloy -4 & Removable & 48 & 6.10 & 524 & 26 & No & Yes (2) \\
\hline$N-1$ & 301 . & zircaloy -4 & Non-Removable & Powder & 7.20 & 47.4 & 31 & No & No \\
\hline $\mathrm{N}-1$ & 302 & Zircaloy-4 & Non-Removable & Powder & 7.20 & $4 \pi$ & 31 & No & No \\
\hline$N-1$ & 303 & Zircaloy -4 & Non-Removable & Powder & 7.20 & 472 & 30 & No & No \\
\hline $\mathrm{N}-1$ & 311. & $304 \mathrm{~s} / \mathrm{s}$ & Non-Removable & Powder & 7.20 & 540 & 34 & No & No \\
\hline$N-1$ & 312 & $304 \mathrm{~s} / \mathrm{s}$ & Hon-Removable & Powder & 7.20 & 543 & 34 & No & No \\
\hline $\mathrm{N}-1$ & $32 i$ & Zirce 10y-4 & Removable & 48 & 6.10 & 528 & 28 & Yes $(1)$ & No \\
\hline $\mathrm{N}-\mathrm{i}$ & 330 & $304 \mathrm{~s} / \mathrm{s}$ & Removable & 48 & $5: 71$ & 578 & 29 & No & No \\
\hline
\end{tabular}

(1) 15 mil diameter hole at region of maximum flux.

(2) Approximately $9000 \mathrm{MWD} / \mathrm{MIT}$. 


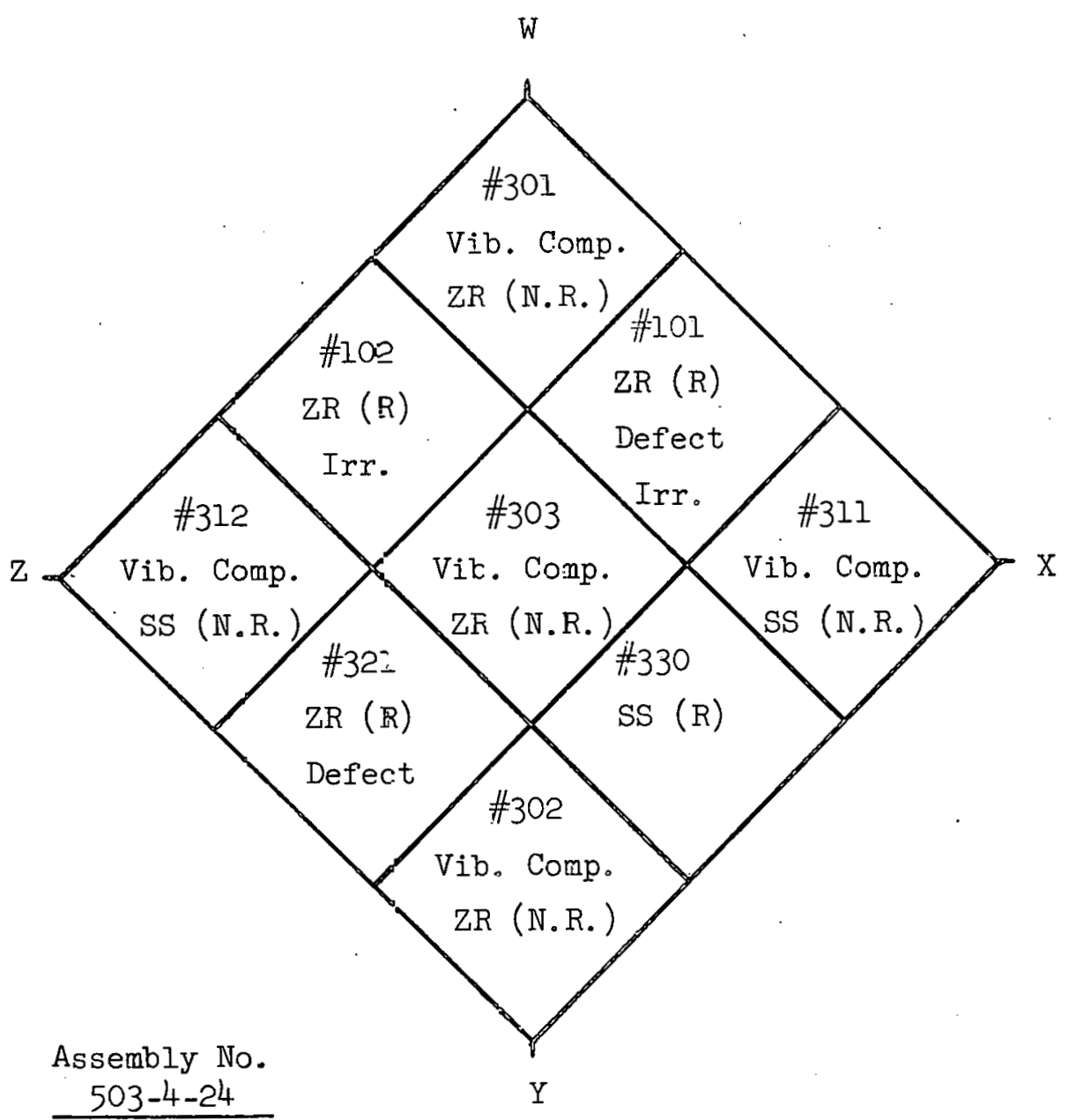

Figure 5 Orientation of the Saxton Special Removable In-Pile 3x3 Defect Test Assembly

$$
\begin{array}{r}
\text { Legend: } \text { ZR - Zircaloy } 4 \text { Clad } \\
\text { SS - } 304 \text { Stainless Steel } \\
\text { N.R. - Non-Removable } \\
\text { R. - Removable } \\
\text { Vib. Comp. - Vibratory Compacted }
\end{array}
$$


The $3 \times 3$ subassembly containing the defected rod was placed in the center of a $9 \times 9$ fuel assembly, No. 503-10-1, as shown in Figure 6, which was located in the Saxton core center, position M-1, 1llustrated in Figure 7 . 


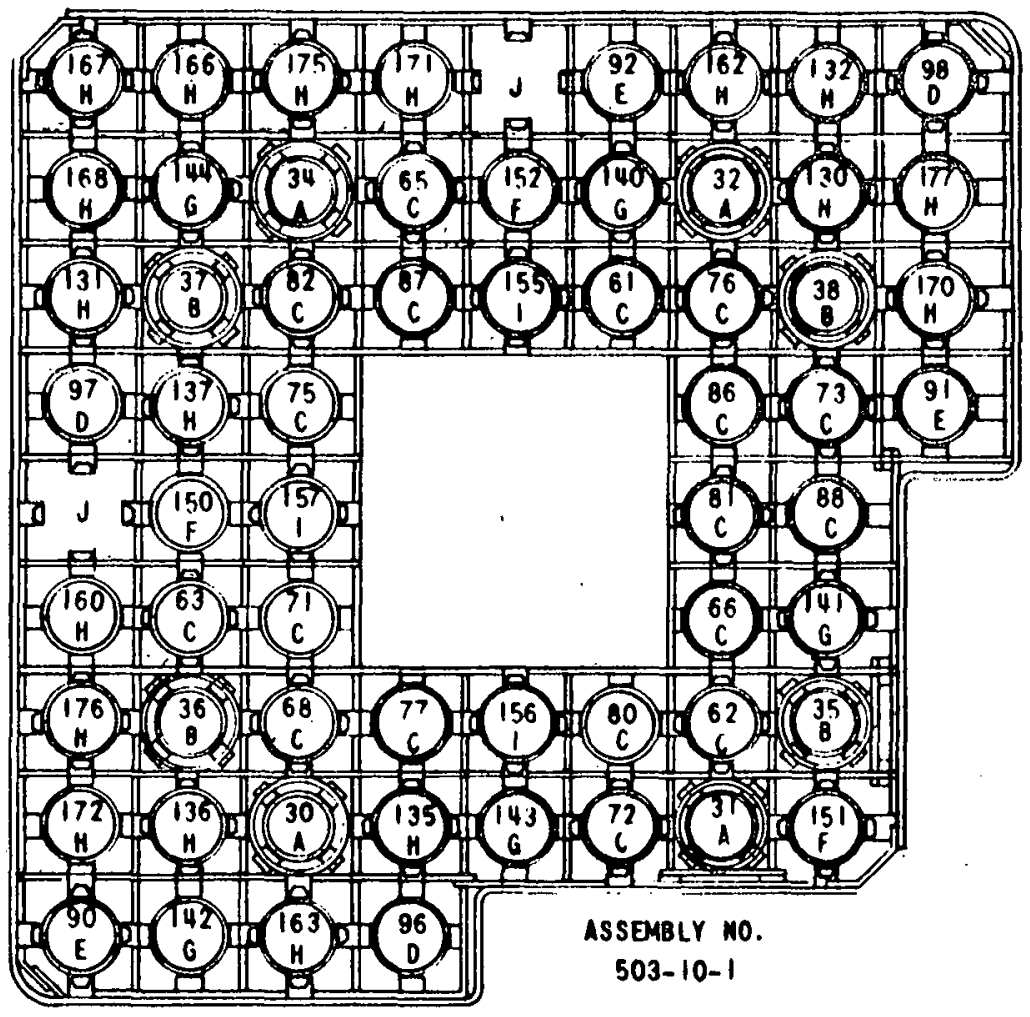

. KEY

ITEMS

A RCC TEST ELEMEAT WITH PERFORATEO QUIDE TUBE

B. RCC TEST ELEMEAT WITH SOLID GUIDE TUBE

C. STAINLESS STEEL CLAD FUEL ROD (i) WITH UO 2 PELLETS (2) ENRICHED TO PROVIDE 16 KW/FT PEAR POWER. OUTPUT

D STAINLESS STEEL CLAD FUEL ROD (1) WITH UO ${ }_{2}$ PELLETS (2) ENRICHED TO PROVIDE 13.5 KW/FT PEAK POAER OUTPUT

E STAINLESS STEEL CLAD FUEL ROO (1) WITH UO ${ }_{2}$ PELLETS (2) ENRICHFN TO PROVIOE 13.5 FH/FT PEAK POWER OUTPUT (5)

F ZIRCALOY CLAD FUEL ROD (3) WITH UO, PELLETS (4) ENRICHED TO PROVIDE $13.5 \mathrm{KW} / \mathrm{FT}$ PEAK POWTR OUTPUT

6. ZIRCALOY CLAD FUEL ROD 131 WITH UO ${ }_{2}$ PELLETS (4) ENRICHED TO PROVIDE $13.5 \mathrm{KW} / F T$ PEAK POWTR OUTPUT

H ZIRCALOY Clad FUEL ROD (3.) WITH UO ${ }_{2}$ PELLETS (4) ENRICHED TO PROVIOE $14 \mathrm{~kW} / \mathrm{Ft}$ PEAK POWER OUTPUT.

I ZIRCALOY CLAD FUCL ROD (a) WITH UO 2 RELLET3 (4) EhRICHED TU PKUVIDE IG KW/FT PEAK POWER OUTPUT

$\checkmark$ BLARK SPACE PROVIDEO fOR IN-CORE INSTRUMENTATION

MOTES:

(1) ALL STAIGLESS CLADOING IS .36I IN 1.0. WITH .015 IN. MALL

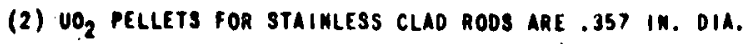

(3) ALL ZIRCALOY CLAODIMG IS .3435 IN. 1.D. WITH .0237 IN. WALL

(4) $\mathrm{UO}_{2}$ PELLETS FOR IIRCALOY CLAD RODS ARE .337 IN. DIA.

(s) UO $\mathrm{O}_{2}$ FUEL PELLETS CONTAIMIMG ICS PPM DOROM

Figure 6

E. D. SK. $302100-B$

End View and Arrangement or 9x9 Fuel Assembly No. 503-10-1 


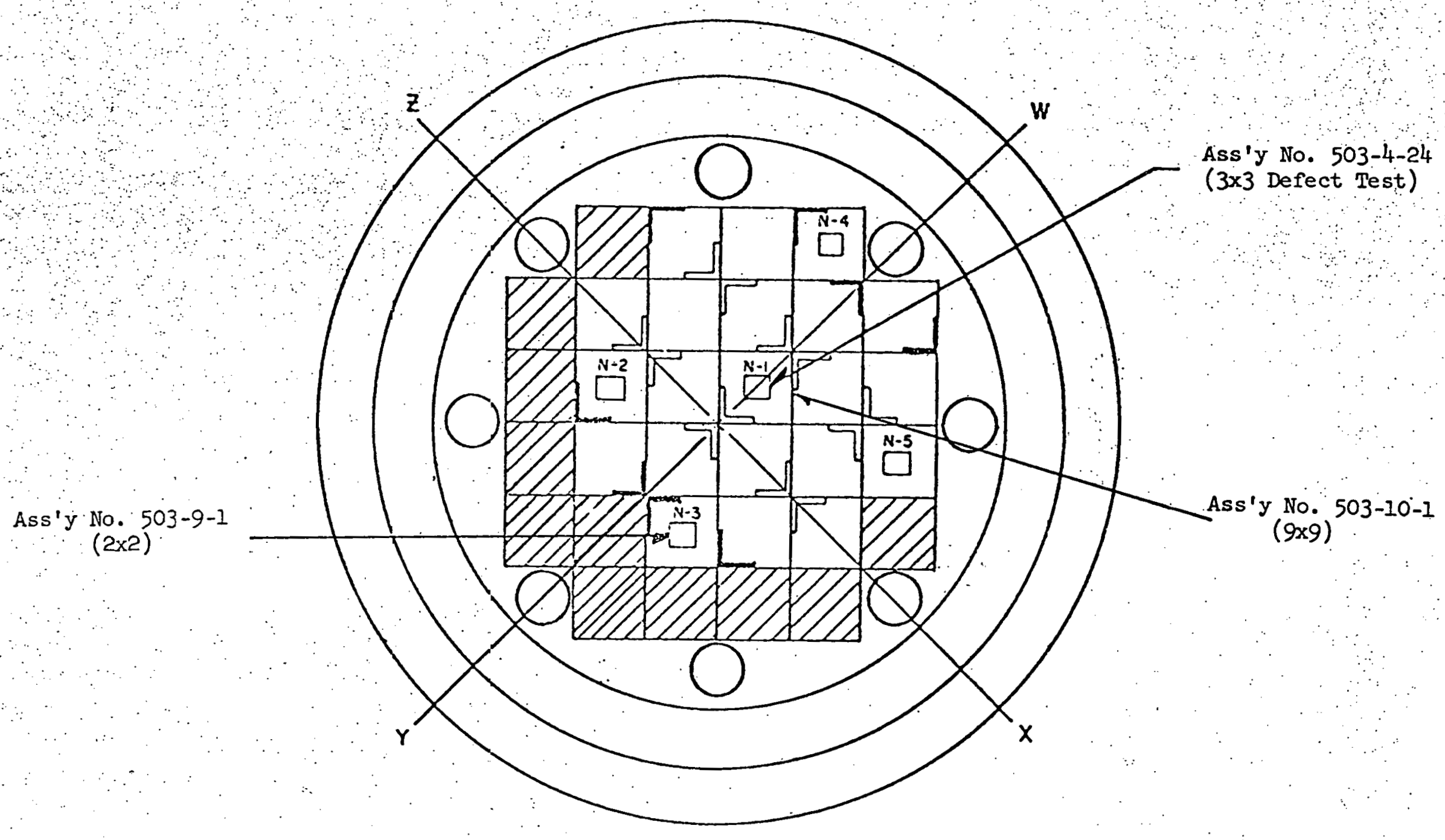

PLART VIEN OF. THE SAXTOII CORE IILUSTRATIIG TIE SAXTON SPECIAI ASSEMBLIES

Figure 7 
III. REACTOR OPERATIONS AND WATER CHEMISTRY

The defected fuel rod in its subassembly was placed in the reactor core during the cold shutdown of July, 1964. The reactor coolant was heated to $\approx 530^{\circ} \mathrm{F}$ on July 30 , and power operation was begun August 12. Numerous plant difficulties caused the reactor to be shutdown several times at first, then on August 15, operation at 20 MWt was sustained for about seven days. This was followed by a shutdown, and then, beginning August 22, the reactor was operated at power without further difficulty, until the final. shutdown for the defect test on October 13, 1964. Plant cooldown was accomplished on October 14, for removal of the $3 \times 3$ defect assembly.

Primary system operations and coolant chemistry are presented in Figure 8 for the period when the defect was in the reactor, i.e., July 30 to October 14, 1964. Coolant chemistry was typically that of a chemical shim plant, with $\approx 600$ ppm boron as boric acid partially neutralized with $\approx 1 \times 10^{-4}$ molal alkali as potassium and lithium hydroxides. Except as noted later, there was no ion exchange purification of the primary coolant. Feed and bleed from the reactor loop through the low pressure surge tank and back to the reactor was not continuous but was initiated during each eight hour period for 10 to 30 minutes at $12 \mathrm{gpm}$. In addition to this, feed and bleed was initiated, following each water or boric acid solution addition, and continued until mixing was complete.

In addition to the chemical quantities given in Figure 8 , the primary coolant contained 25-35 cc $\mathrm{H}_{2}$ (STP)/ $\mathrm{kg}$ coolant, and daily analyses showed there was no oxygen in the coolant, i.e.., less than $0.010 \mathrm{ppm}$. 


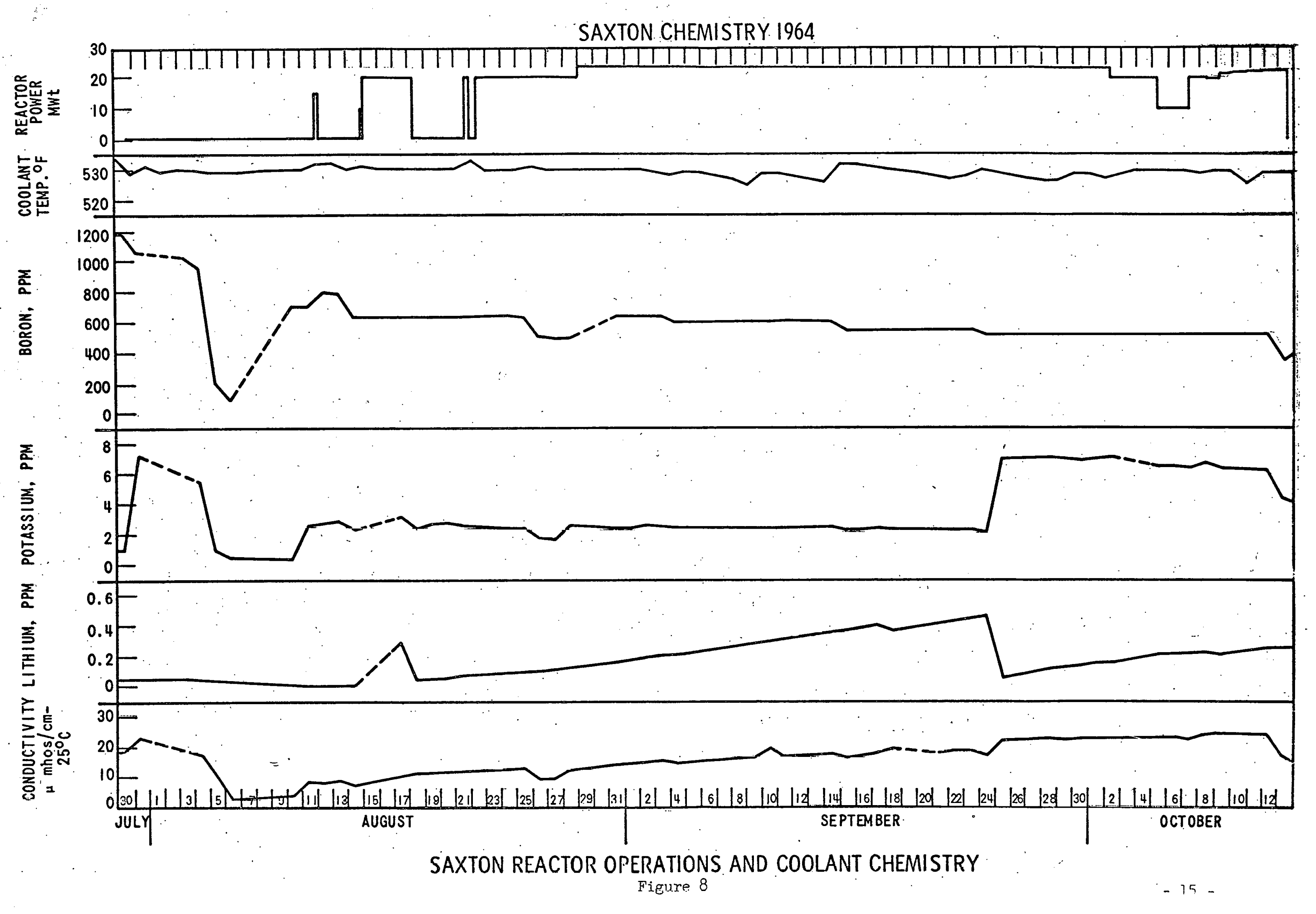


SAXTON CHEMISTRY 1964

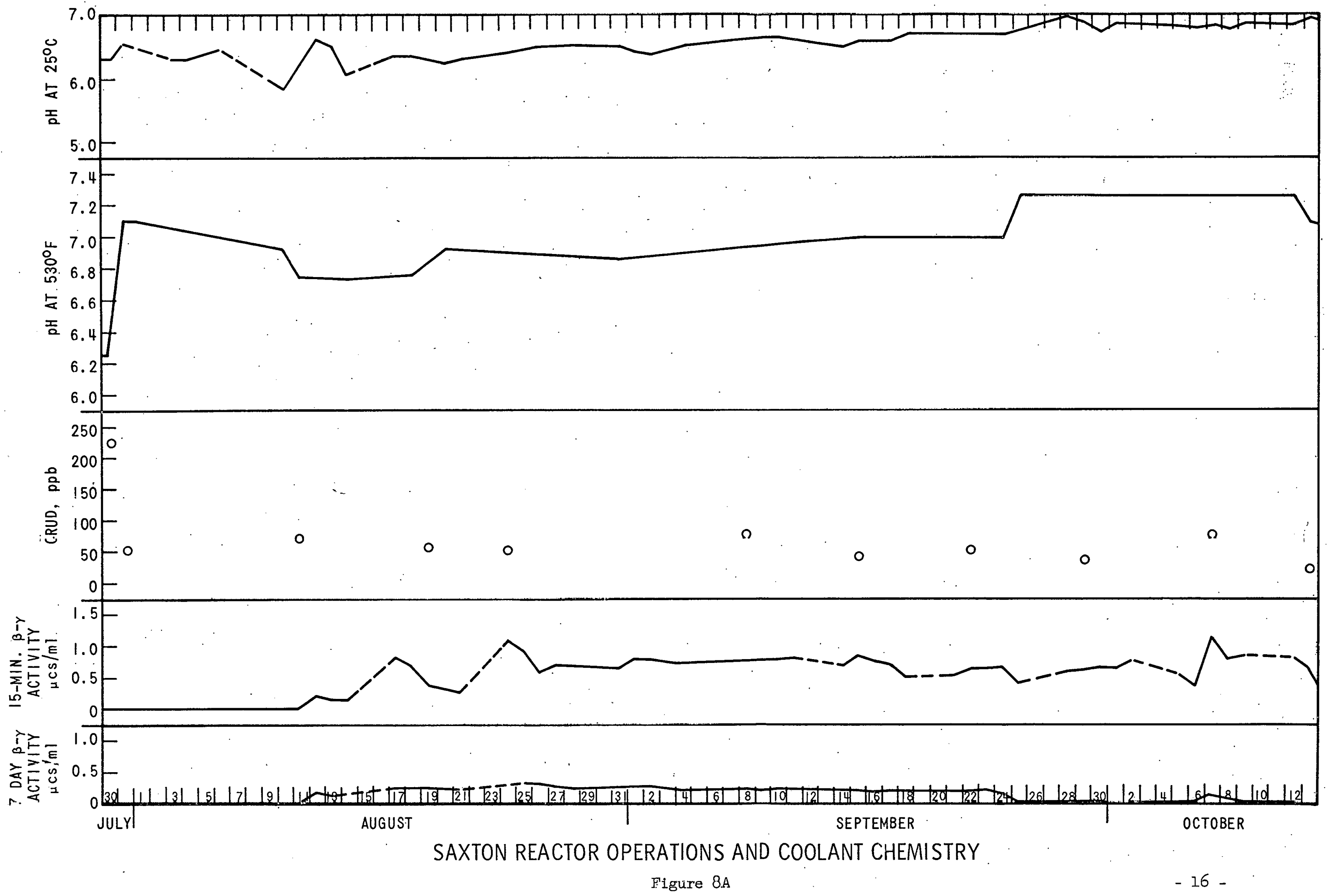


Near the end of September, the coolant demineralizer was placed in continuous service at $11.5 \mathrm{gpm}$ flow for a period of about 12 hours. This was done in order to define, if possible, the contamination factors or removal efficiencies for fission products across the ion exchanger. The ion exchanger material was $6 \mathrm{cu}$. ft. of Illco NR-9 mixed bed resin regenerated in the potassium/borate forms, and was contained in a vessel having an internal diameter of 24 .inches. 
IV. SAMPLE ANALYSIS AND TEST RESULTS

During the period August 1.2 to October 25, samples of the primary coolant were collected and analyzed for fission products. Liquid coolant samples are collected at Saxton from a special sample line that connects into the loop piping between the primary coolant pump and the reactor vessel. This sample travels hot to the sample room where it may be cooled and collected in an appropriate sample vessel. For samples to be analyzed for ionic fission products such as iodine and cesium, the sample is cooled and collected in a clean polyethylene bottle. For analysis of dissolved gaseous fission products, such as xenon, the sample is isolated in a stainless steel vessel before cooling, and the vessel removed to the laboratory for gas stripping. The specific techniques used for radiochemical analysis of samples is given in Appendix A, Radiochemical Analysis of Solutions, and Appendix B, Separation and Analysis of Fission Gases from Solution Samples.

Results of coolant sampling during the test are presented in Table 3 for the period with no purification, and Table 4 for the 13 hours of coolant purification. The data of Table 3 is also presented in t'igure y Iur fission products $I^{131}, I^{133}, 15 \mathrm{~m}, \beta-\gamma$ coolant activity, reactor power, and coolant makeup. These data will be utilized to assess the escape rates of fission products from the defected fuel, rod, given in following sections. 


\begin{tabular}{|c|c|c|c|c|c|c|c|c|c|c|}
\hline $\begin{array}{c}\text { Date/Time } \\
1964 \\
\end{array}$ & $\begin{array}{l}\text { Reactor } \\
\text { Power } \\
\text { MWt } \\
\end{array}$ & $\begin{array}{c}I^{131} \\
\mathrm{dpm} / \mathrm{cc} \text { Coolant }\end{array}$ & $\begin{array}{r}I^{131} \\
\nu, \sec ^{-1} \\
\end{array}$ & $\begin{array}{c}\mathrm{I}^{133} \\
\mathrm{dpm} / \mathrm{cc} \text { Coolant } \\
\end{array}$ & $\begin{array}{c}I^{133} \\
\nu_{2} \sec ^{-1} \\
\end{array}$ & $\begin{array}{c}I^{135} \\
\mathrm{dpm} / \mathrm{cc} \text { Coolant } \\
\end{array}$ & $\begin{array}{c}I^{135} \\
\nu, \sec ^{-1} \\
\end{array}$ & $\begin{array}{l}\text { Atom Ratio } \\
I^{131} / I^{133} \\
\end{array}$ & $\begin{array}{l}\text { Atom Ratio } \\
I^{131} / I^{135} \\
\end{array}$ & $\begin{array}{l}\text { Atom Ratio } \\
I^{133} / I^{135} \\
\end{array}$ \\
\hline $8-15 / 1100$ & 20 & $1.38 \times 10^{5}$ & $0.90 \times 10^{-9}$ & $25.3 \times 10^{5}$ & $69.3 \times 10^{-9}$ & & . & $0.51 \because \therefore$ & 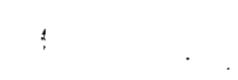 & \\
\hline 1135 & 20 & $0.38 \times 10^{5}$ & $0.24 \times 10^{-9}$ & & & & & . & 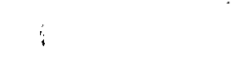 & \\
\hline 2300 & 20 & $0.60 \times 10^{5}$ & $0.40 \times 10^{-9}$ & $5.07 \times 10^{5}$ & $13.7 \times 10^{-9}$ & & & .1 .10 & $\vdots$ & \\
\hline $8-16 / 11100$ & 20 & $1.13 \times 10^{5}$ & $0.74 \times 10^{-9}$ & $8.52 \times 10^{5}$ & $23.0 \times 10^{-9}$ & & $\therefore \quad:$ & 1.23 & 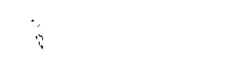 & \\
\hline 2300 & 20 & $1.08 \times 10^{5}$ & $0.70 \times 1.0^{-9}$ & $6.52 \times 10^{5}$ & $17.6 \times 10^{-9}$ & & & 1.54 & $:$ & \\
\hline $8-17 / 1100$ & 20 & $1.17 \times 10^{5}$ & $0.76 \times 10^{-9}$ & $5.00 \times 10^{5}$ & $13.5 \times 10^{-9}$ & 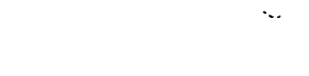 & & 2.07 & $\because$ & \\
\hline 2300 & 20 & $1.25 \times 10^{5}$ & $0.81 \times 10^{-9}$ & $4.42 \times 10^{5}$ & $11.9 \times 10^{-9}$ & & & 2.62 & & \\
\hline $8-18 / 0752$ & 20 & $1.39 \times 10^{5}$ & $0.91 \times 10^{-9}$ & $4.10 \times 10^{5}$ & $11.0 \times 10^{-9}$ & $1.33 \times 10^{5}$ & $12.6 \times 10^{-9}$ & 3.14 & 30.1 & 9.7 \\
\hline 1000 & 20 & $1.35 \times 10^{5}$ & $0.88 \times 10^{-9}$ & $3.95 \times 10^{5}$ & $10.6 \times 10^{-9}$ & $0.95 \times 10^{5}$ & $9.01 \times 10^{-9}$ & 3.17 & 40.8 & 12.9 \\
\hline $8-22 / 1800$ & 20 & $13.4 \times 10^{5}$ & $8.90 \times 10^{-9}$ & & & & & & $\therefore$ & \\
\hline $8-23 / 1800$ & 20 & $12.9: \times 10^{5}$ & $8.50 \times 10^{-9}$ & & & & & & $\vdots$ & \\
\hline $8-24 / 1800$ & 20 & $12.4 \times 10^{5}$ & $8.19 \times 10^{-9}$ & & & & & & $\vdots$ & \\
\hline $8-25 / 1930$ & 20 & $10.7 \times 10^{5}$ & $7.04 \times 10^{-9}$ & & & & & & & \\
\hline $8-27 / 1100$ & 20 & $6.39 \times 10^{5}$ & $4.15 \times 10^{-9}$ & $1.02 \times 10^{5}$ & $2.74 \times 10^{-9}$ & $2.28 \times 10^{5}$ & $21.7 \times 10^{-9}$ & 58 & $\therefore 81$ & 1.4 \\
\hline $8-27 / 1552$ & 20 & $6.02 \times 10^{5}$ & $3.92 \times 10^{-9}$ & $1.18 \times 10^{5}$ & $3.18 \times 10^{-9}$ & $.1 .78 \times .10^{5}$ & $16.9 \times 10^{-9}$ & 47 & $: 98$ & P. 1 \\
\hline $8-28 / 0825$ & 20 & $6.56 \times 10^{5}$ & $4.27 \times 10^{-9}$ & $1.29 \times 10^{5}$ & $3.48 \times 10^{-y}$ & $1.00 \times 10^{5}$ & $9.49 \times 10^{-9}$ & & 189 & 4.0 \\
\hline $9-8 / 1015$ & 23.5 & $3.90 \times 10^{5}$ & $2.21 \times 10^{-9}$ & & & & & & & \\
\hline $9-11 / 1045$ & 23.5 & $4.31 \times 10^{5}$ & $2.39 \times 10^{-9}$ & & & & & & 3 & \\
\hline $9-16 / 1030$ & 23.5 & $3.98 \times 10^{5}$ & $2.21 \times 10^{-9}$ & & & & & & ; & \\
\hline $9-18 / 1030$ & 23.5 & $3.94 \times 10^{5}$ & & & & & & & & \\
\hline $9-21 / 1000$ & 23.5 & $2.71 \times 10^{5}$ & $1.77 \times 10^{-9}$ & & & & & & $\because$ & \\
\hline $9-23 / 1015$ & 23.5 & $3.79 \times 10^{5}$ & $2.10 \times 10^{-9}$ & $0.46 \times 10^{5}$ & $1.09 \times 10^{-9}$ & & & 76 & . & \\
\hline 1515 & 23.5 & $4.15 \times 10^{5}$ & $2.30 \times 10^{-9}$ & $0.67 \times 10^{5}$ & $1.54 \times 10^{-9}$ & & & 58 & & \\
\hline $9-24 / 0845$ & 23.5 & $3.35 \times 10^{5}$ & $2.20 \times 10^{-9}$ & $0.97 \times 10^{5}$ & $2.22 \times 10^{-9}$ & & & 37 & $\vdots$ & \\
\hline
\end{tabular}


TABLE 4

Fissicn Product Activity in Saxton Coolant vith Purification

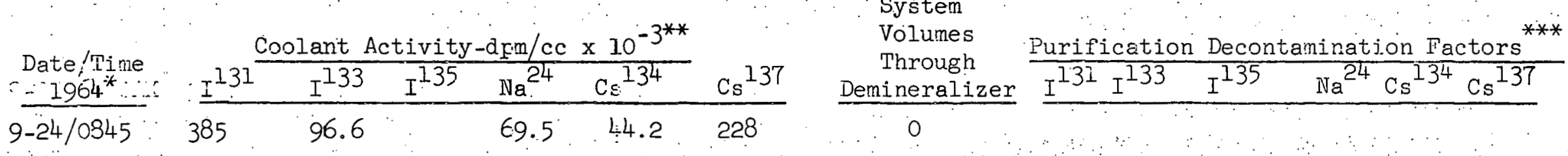

$$
\begin{aligned}
& / 1010 \text { Purification flow begun at } 11.5 \mathrm{gpm} \text { - Reactor at } 23.5 \mathrm{MWt}
\end{aligned}
$$

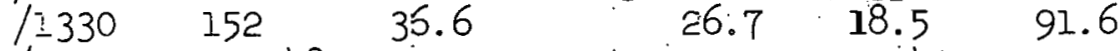

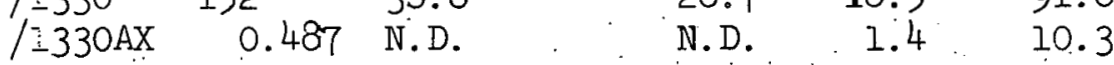

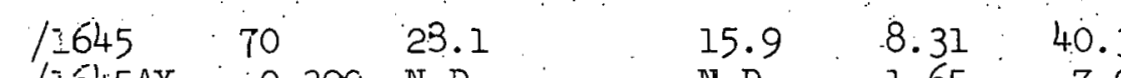

$$
\begin{aligned}
& 1=545 \mathrm{AX} \quad 0.390 \text { N.D. N.D. } 1.65 \quad 7.9 \\
& \begin{array}{lllllll}
0 & /=930 & 31.2 & 1+.9 & 10.9 & 4.12 & 25.8 \\
1 & /=930 \mathrm{AX} & 0.073 & \text { N.D. } & 1.18 & 1.61 & 8.24
\end{array} \\
& \begin{array}{lllllll}
12200 & 19.1 & 12.3 & 11.3 & 1.01 & 2.87 & 14.0
\end{array} \\
& 12200 A X \\
& 0.069 \text { N.D. } \\
& \text { N.D. N.D. } \\
& 1.21 \quad 7.61 \\
& 0.91 \\
& 312>360 \\
& >\begin{array}{llll}
270 & 13 & 8.9
\end{array} \\
& 12210 \\
& \text { Purification flow ended } \\
& 38 . \\
& 50.5 \\
& 19.1 \\
& 33.5 \\
& 2.88 \\
& 13.7
\end{aligned}
$$


Figure 9

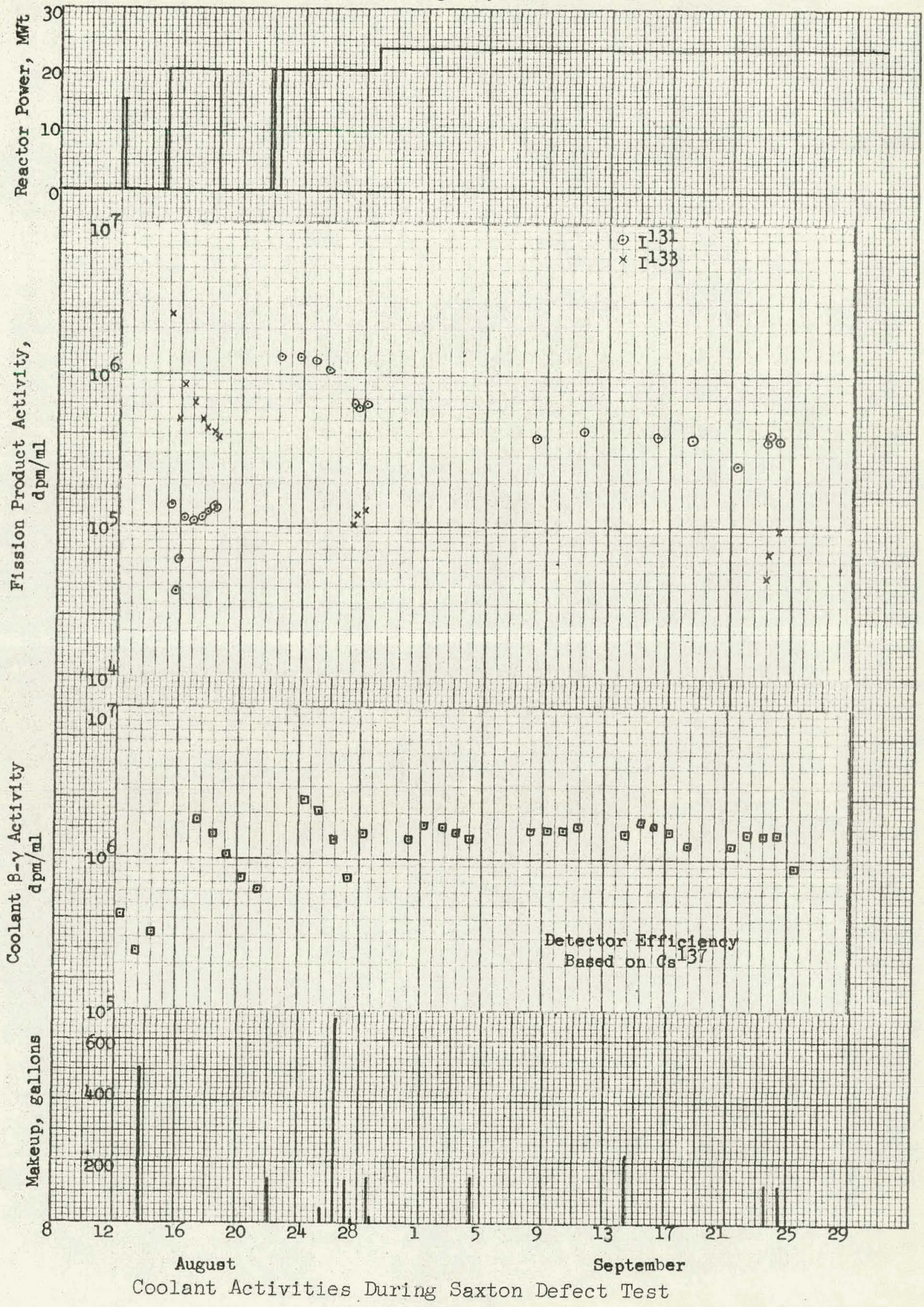


V. MATHEMATICAL ANALYSIS OF FISSION PRODUCT DATA

A simple model for escape of fission products from a defective fuel element is presented, which permits analysis of the data given in Table 8 . The model assumes ideal conditions in most every parameter chosen, and should, therefore, not be construed as a display of rigorous equations which take into account all variables. For example, use of the constant $\nu$, the escape rate coefficient, is made without regard to a possible variation in its value with reactor power or temperature." This coefficient is simply an "apparent" release-rate, whether the release is controlled by defect size or by diffusion of fission products from the fuel pellets, or both. (Amplification of the definition of the escape rate coefficient can be found in the literature $\frac{2,3}{2}$ ) A glossary of terms used in the model follows:

$$
\begin{aligned}
N & =\text { total atoms of nuclide } \\
F & =\text { fission rate in defective element, fissions/sec } \\
P_{D} & =\text { defect power, per cent } \\
P_{t} & =\text { reactor power, watts thermal. } \\
Y & =\text { risslor yleld of primary fission product } \\
\lambda & =\text { decay constant, sec }{ }^{-1} \\
\nu & =\text { escape rate coefficient, sec }{ }^{-1} \\
k_{p} & =\text { purlfication constant for fission product, } \mathrm{sec}^{-1} \\
\mathrm{k}_{I} & =\text { leakage constant of gas from coolant, } \mathrm{sec}^{-1} \\
t & =\text { time, seconds } \\
F_{I X} & =\text { ion exchange flow rate, gpm } \\
V_{T} & =\text { total coolant volume (reduced to STP), gallons } \\
F_{P} & =\text { spray flow to pressurizer, gpm } \\
A & =\text { coolant specific activity for nuclide, dpm/ml }
\end{aligned}
$$




\section{Subscripts}
$A .=$ primary fission product
$B=$ daughter product

\section{Superscripts}

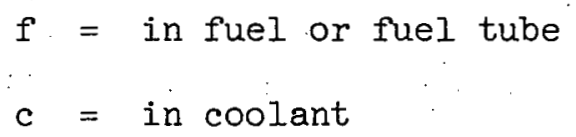

From Table 5 it is seen that the decay chains may be conveniently divided in terms of "primary fission products" and "daughter products". The latter arise from decay of primary fission products, and are assumed to be produced in no significant yield by the fissioning process. Thus', the following nuclides have been so divided:

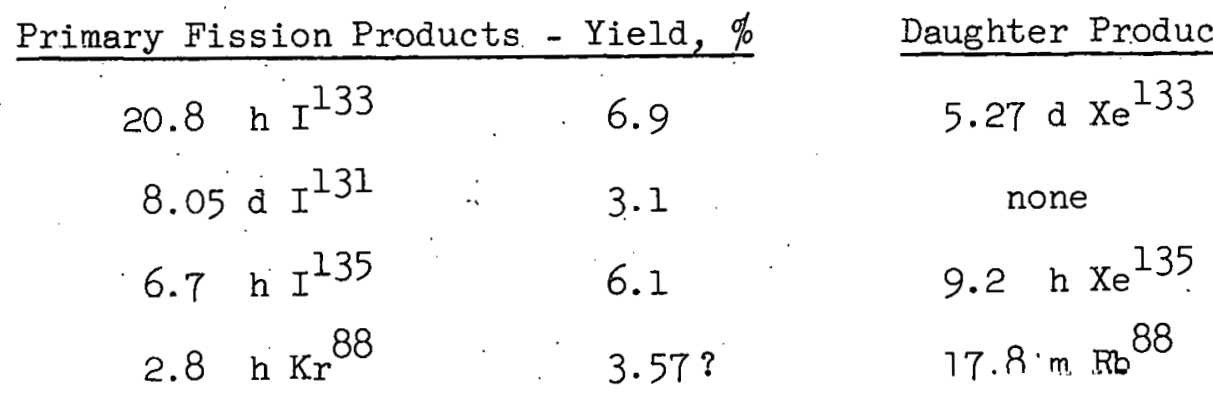

As seen from Table 5, there is some uncertainty in the yield of $\mathrm{Kr}^{88}$ since it appears in the 89 decay scheme, as well as, the 88 sehelle. Moreover, the direct yield of $\mathrm{Kr}^{88}$ is assumed to be equal to the total chain yield which is reported only for $\mathrm{sr}^{88}$. 


\section{FISSION PRODUCT DECAY SCHEMES *}

a. 133

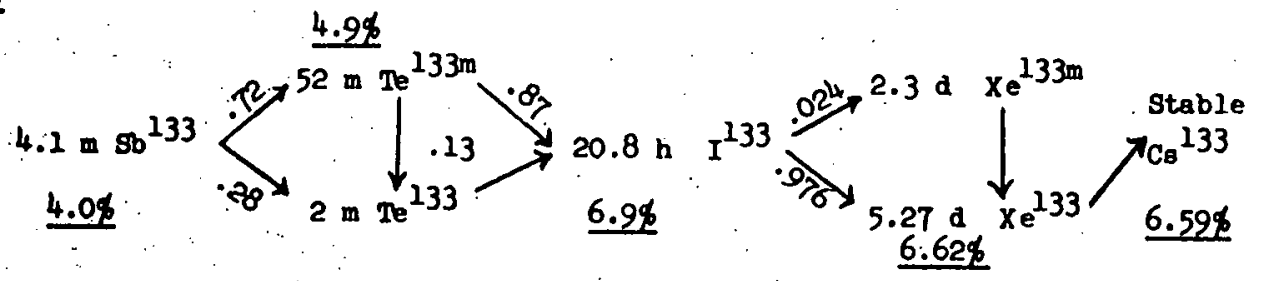

b. 131

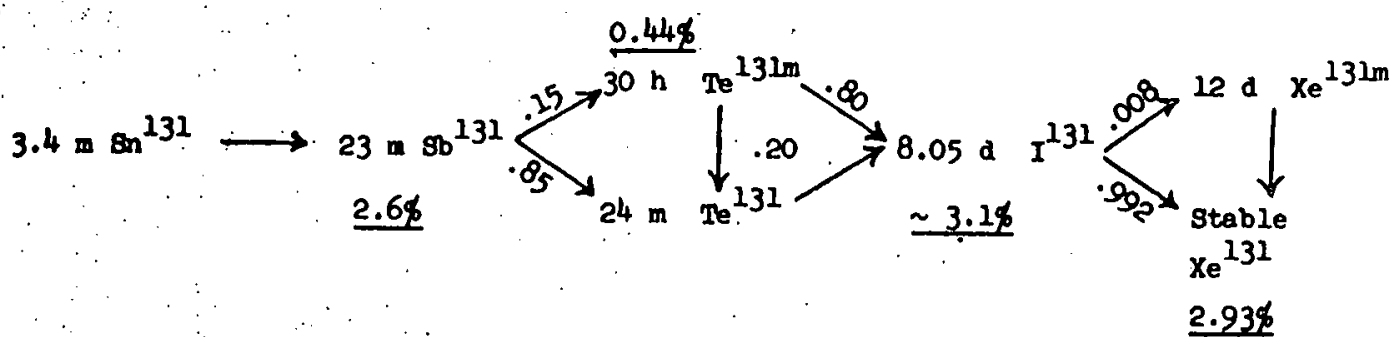

c. 135

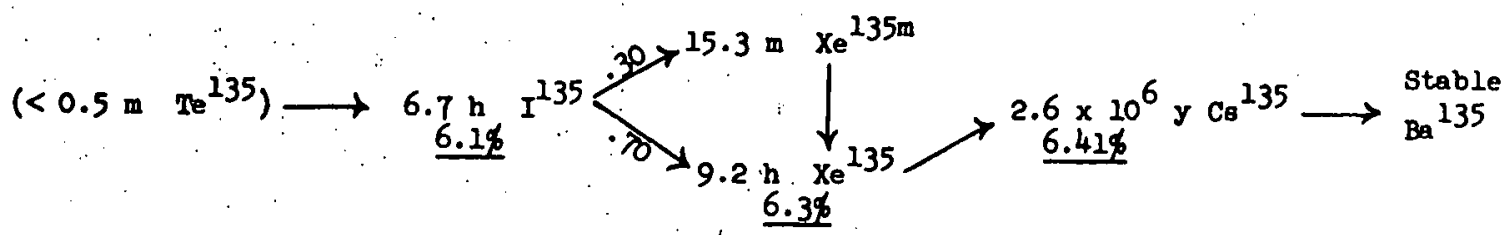

d. 88

$15.5 \mathrm{mar} \mathrm{Kr}^{8.7}+\mathrm{o}^{\mathrm{n}^{1}}$

e. 89

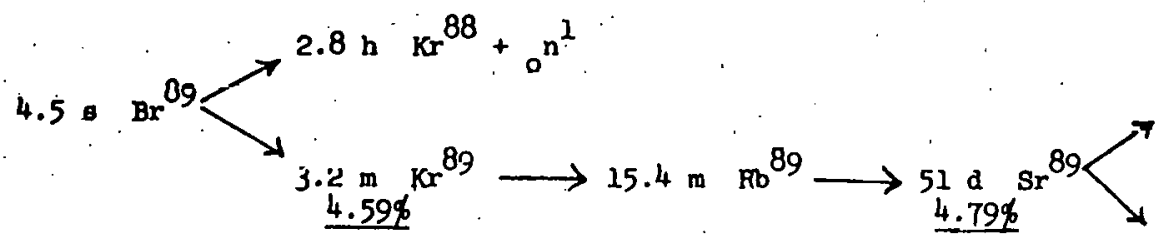

s. Katcorf, "Fission Product Yields from Neulron-Inducen Fieaion", NUCLEONICS, 18 , 2nI (1060).

NOTE: Experimental. fission ylelda, in per cent. are underlined. 
With the foregoing as a basis, therefore, a model for the escape of fission and daughter products from the defective fuel element can be constructed. The mechanism is visualized as follows:

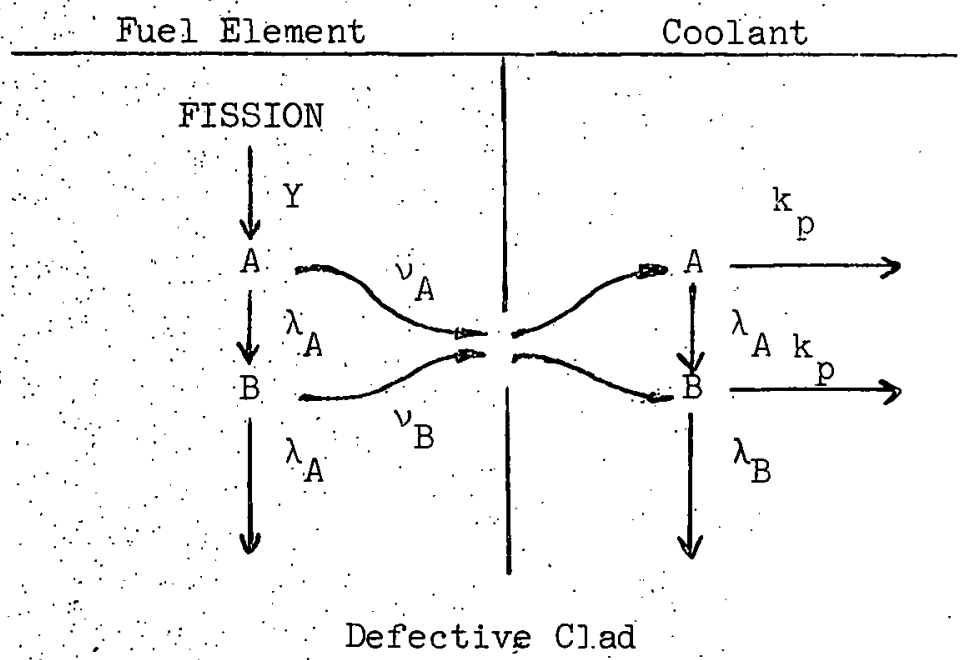

where primary fission products (A) are produced from fission at a yield, $Y$, and undergo decay, $\lambda$, and escape to the coolant, $\nu$. The daughter product (B) follows a similar model. Both the primary fission product and the daughte " pruduct can be removed from the coolant by either purification, or by leakage. The expressions which describe the model of fissivi product release are derived in the following:

IN FUEL TUBE

\begin{tabular}{|c|c|}
\hline $\begin{array}{l}\frac{\text { PRTMARY FISSION }}{d N_{A}^{f}} \frac{\text { PRODUCT }}{d t}=F_{A}-N_{A}^{f} \lambda_{A}-N_{A}^{f} \nu_{A}=0 \\
\text { at steady state } \\
N_{A}^{f}=\frac{F_{A}}{\left(\lambda_{A}+v_{A}\right)}\end{array}$ & $\begin{array}{l}\frac{\text { DAUGHTER PRODUCT }}{\mathrm{d}: \mathrm{N}_{\mathrm{B}}^{\mathrm{f}}} \\
\frac{\mathrm{d}}{\mathrm{dt}}=\mathrm{N}_{\mathrm{A}}^{\mathrm{f}} \lambda_{\mathrm{A}}-\mathrm{N}_{\mathrm{B}}^{\mathrm{f}} \lambda_{\mathrm{B}}-\mathrm{N}_{\mathrm{B}}^{\mathrm{f}} \cdot \nu_{\mathrm{B}}=0 \text {, at steady } \\
\text { state. } \\
\text { Combine with (1) } \\
\mathrm{N}_{\mathrm{B}}^{\mathrm{f}}=\frac{\mathrm{FY}_{\mathrm{A}} \lambda_{\mathrm{A}}}{\left(\lambda_{\mathrm{A}}+\nu_{\mathrm{A}}\right)\left(\lambda_{\mathrm{B}}+\nu_{\mathrm{B}}\right)}\end{array}$ \\
\hline
\end{tabular}




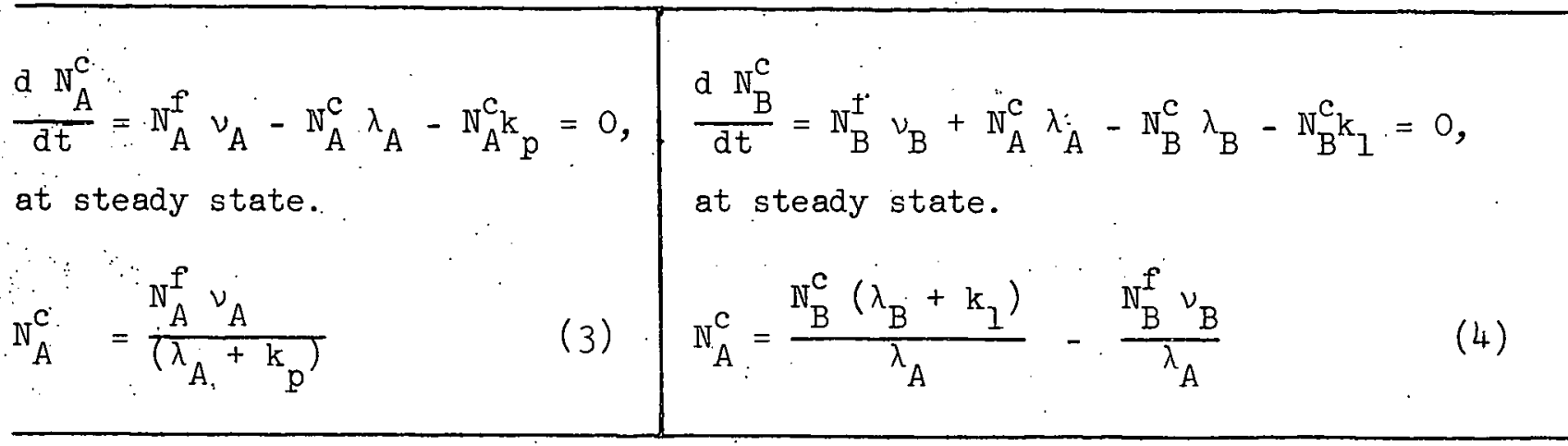

For the quantity of primary and daughter products in the coolant, first combine (1) and (3) to obtain

$$
\mathrm{N}_{\mathrm{A}}^{\mathrm{C}}=\frac{{ }_{\mathrm{AY}} \nu_{\mathrm{A}}}{\left(\lambda_{\mathrm{A}}+\nu_{A}\right)\left(\bar{\lambda}_{A}: \mathrm{k}_{\mathrm{p}}\right)}
$$

and (2) and (4) to obtain

$$
\mathrm{N}_{\mathrm{A}}^{\mathrm{C}}=\frac{\mathrm{N}_{\mathrm{B}}^{\mathrm{c}}\left(\lambda_{\mathrm{B}}+\mathrm{k}_{1}\right)}{\bar{\lambda}_{\mathrm{A}}} \cdot \frac{\mathrm{FY}_{\mathrm{A}} \nu_{\mathrm{B}}}{\left(\lambda_{\mathrm{A}}+\nu_{\mathrm{A}}\right)\left(\lambda_{B}+\nu_{B}\right)}
$$

then combinc (j) alld (5), which yields:

$$
\left.\mathrm{N}_{D}^{\mathrm{C}}=\frac{F Y_{A} \lambda_{A}}{\left(\lambda_{B}+k_{l}\right)\left(\lambda_{A}+\nu_{A}\right)}\left[\frac{\nu_{A}}{\left(\lambda_{A}+k_{p}\right.}\right)+\frac{\nu_{B}}{\left(\lambda_{B}+\nu_{B}\right)}\right]
$$

Thus, equations (5) and (7) give the total primary or daughter nucl.ide in the coolant in terms of constants which either may be assumed, or may be determined by independent measurement. The equations are very useful in estimating the ficoions afrected by the defect, and the ratios of escape rate coefficients for various nuclides, provided radiochemistry data is obtained during periods of steady-state operation. For example, 
equation (5) yields the fissions affected, after rearrangement to,

$$
F=\frac{N_{A}^{c}\left(\lambda_{A}+\nu_{A}\right)\left(\lambda_{A}+k_{p}\right)}{\nu_{A}{ }^{\nu} A}
$$

provided, of course, $\mathrm{N}_{\mathrm{A}}^{\mathrm{C}}$ is determined at steady state, and an estimate is made for the escape rate coefficient, $\nu_{A}$. Conversely, if the defect power or fissions-affected are known, an estimate of the escape rate coefficient may be made by rearrangement of equation (5) to

$$
\nu_{A}=\frac{\beta \lambda_{A}}{1-\beta} \text {, where } \beta=\frac{N_{A}^{c}\left(\lambda_{A}+k_{p}\right)}{F_{A} Y_{A}}
$$

Now, the ratio of any two primary fission products in the coolant, at steady-state, is given from equation (5) as

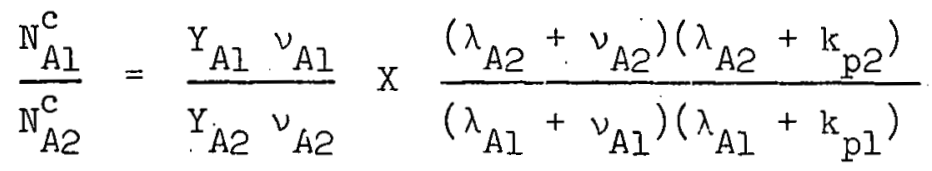

The ratio of daughter to primary products in the coolant is obtained from equations (5) and (7), which, after collecting terms, gives

$$
\frac{N_{B}^{c}}{N_{A}^{c}}=\left[\frac{\lambda_{A}}{\left(\lambda_{B}+k_{1}\right)}+\frac{\nu_{B}\left(\lambda_{A}+k_{p}\right) \lambda_{A}}{\nu_{A}\left(\lambda_{B}+k_{1}\right)\left(\lambda_{B}+\nu_{B}\right)}\right]
$$

Moreover, it is readily seen that the escape rate coefficient of either the primary product or the daughter product may be determined, relative to the other, by rearrangement of equation (11) to the following

$$
\nu_{A}=\frac{\nu_{B}}{\alpha\left(\lambda_{B}+\nu_{B}\right)}
$$


or

$$
v_{B}=\frac{\alpha \lambda}{\left(\frac{1}{v_{A}}-\alpha\right)}
$$

where

$$
\alpha=\frac{\mathrm{N}_{\mathrm{B}}^{\mathrm{c}}\left(\lambda_{\mathrm{B}}+\mathrm{k}_{\mathrm{L}}\right)-\mathrm{N}_{\mathrm{A}}^{\mathrm{C}} \lambda_{\mathrm{A}}}{\mathrm{N}_{\mathrm{A}}^{\mathrm{C}} \lambda_{\mathrm{A}}\left(\lambda_{\mathrm{A}}+\mathrm{k}_{\mathrm{p}}\right)}
$$

The equations given above should represent most of those which are needed to analyze a defect from the amount of activity appearing in the coolant at steady state. A summary of these equations is given in Table 6. 


\begin{tabular}{r}
\hline 1. Fissions Affected \\
$F=\frac{\mathrm{N}_{A}^{\mathrm{C}}\left(\lambda_{A}+v_{A}\right)\left(\lambda_{A}+k_{P}\right)}{Y_{A} \nu_{A}}$
\end{tabular}

As sumpt1on日*

2. Coolant Activity

a. Primary Fiasion Product

$$
\mathrm{N}_{\mathrm{A}}^{\mathrm{c}}=\frac{\mathrm{FY}_{\mathrm{A}} \nu_{\mathrm{A}}}{\left(\lambda_{\mathrm{A}}+\nu_{\mathrm{A}}\right)\left(\lambda_{\mathrm{A}}+\mathrm{k}_{\mathrm{p}}\right)}
$$

F, $v_{A}$

b. Daughter Product

$$
\mathrm{N}_{B}^{c}=\frac{F Y{ }_{A} \lambda_{A}}{\left(\lambda_{B}+k_{1}\right)\left(\lambda_{A}+\nu_{A}\right)}\left[\frac{\nu_{A}}{\left(\lambda_{A}+k_{p}\right)}+\frac{\nu_{B}}{\left(\lambda_{B}+\nu_{B}\right)}\right]
$$

$F ; v_{A^{\prime}} v_{B}$

3. Coolant Activity Ratios

a. Primary to Primary F1ssion Products

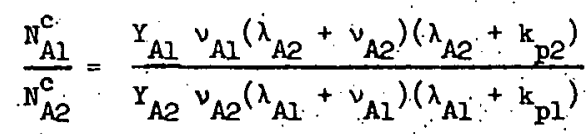

$$
\nu_{A 1}, \nu_{A 2}
$$

b. Daughter to Primary F1oolon Product

$$
\frac{N_{B}^{C}}{N_{A}^{C}}=\frac{\lambda_{A}}{\left(\lambda_{B}+k_{1}\right)}+\frac{\nu_{R} \lambda_{A}\left(\lambda_{A}+k_{P}\right)}{v_{A}\left(\lambda_{B}+k_{1}\right)\left(\lambda_{B}+v_{B}\right)}
$$

$$
v_{A}, v_{B}
$$

4. Escape Rate Coefficlents

a. Primary Flosion Product

$$
\nu_{A}=\frac{B \lambda_{A}}{(1-\beta)} \text {, where } \beta=\frac{N_{A}^{c}\left(\lambda_{A}+k_{P}\right)}{F Y_{A}}
$$

b. Ratio of Daughter to Primary F1ssion Product

$$
\begin{aligned}
& v_{A}=\frac{v_{B}}{\alpha\left(\lambda_{B}+v_{B}\right)} \\
& \text { or } \\
& v_{B}=\frac{\alpha \lambda_{B}}{\left(\frac{1}{v_{A}}-\alpha\right)} \\
& \text { where } \\
& \alpha=\frac{N_{B}^{c}\left(\lambda_{B}+k_{1}\right)-N_{A}^{c} \lambda_{A}}{N_{A}^{c} \lambda_{A}\left(\lambda_{A}+k_{B}\right)}
\end{aligned}
$$

To solve a given equation, it is expected that all variables can be measured or approximatad except those stated in this.column, and in some cases, these too may be assumed. 
VI. ANALYSIS OF DATA COLLECTED DURING DEFECT TEST

In the preceeding section, equations were developed which will permit an analysis of fission product data collected during the defect test. For the most part, calculations can be made to assess the apparent escape rate coefficient, $\nu$, for fission product iodines, based on coolant activities during periods of steady-state reactor operation. These calculations follow:

The escape rate coefficients for primary fission products, such as $I^{131}, I^{133}$, or $I^{135}$, are determined with Eqn.9, i.e.,

$$
\nu_{A}=\frac{\beta \lambda_{A}}{(1-\beta)} \text { where } \beta=\frac{N_{A}^{c}\left(\lambda_{A}+k_{p}\right)}{{ }_{A}}
$$

To solve this equation, use is made of the quantities given in Table 7, which, for the defect test data, give

a. F, fissions affected (considering one defective fuel rod at $13.5 \mathrm{kw} / \mathrm{ft}$ peak, and peak to average of 1.387 , re. Table 1)

$$
\begin{aligned}
\text { Defect Power } & =\frac{13.5 \mathrm{kw} / \mathrm{ft}(\text { peak at } 23.5 \mathrm{MWt})}{(1.387 \text { peak/average })} \times \frac{34.9 \mathrm{in} \text {. fuel }}{(12 \mathrm{in} / \mathrm{ft})(\text { ?3. 5MWt })} \\
& =1.205 \mathrm{kw} / \mathrm{MWt} \\
\mathrm{F} & =\frac{(1.205 \mathrm{kw} / \mathrm{MWt})\left(10^{-6} \mathrm{MWt} / \text { watt }\right)\left(10^{3} \text { watts } / \mathrm{kw}\right) \mathrm{P}_{\mathrm{t}}}{\left(3.2 \times 10^{-11} \text { watt wecc } / \mathrm{fission}\right)} \\
& =3.76 \times 10^{7} \mathrm{P}_{\mathrm{t}}
\end{aligned}
$$

b. $\mathrm{N}_{\mathrm{A}}^{\mathrm{C}}$, atoms of nuclide in coolant,

$$
\mathrm{N}_{A}^{c}-\frac{\left(A_{A}^{c}\right)\left(V_{T}\right)}{\left(\lambda_{A}\right)(60)}
$$


TABLE 7

Constants Used in Fission Product Analysis

\begin{tabular}{|c|c|c|c|c|}
\hline Nuclide & Half-Life & $\begin{array}{l}\text { Fission Yield } \\
\text { Per Cent }\end{array}$ & Decay Constant, $\sec ^{-1}$ & $\begin{array}{c}\text { Cross Section } \\
\sigma \text {, barns }\end{array}$ \\
\hline$I-131$ & $8.05 \mathrm{~d}$ & $\approx 3.1$ & $9.96 \times 10^{-7}$ & - \\
\hline $\begin{array}{l}I-133 \\
I-135 \\
X e-133\end{array}$ & $\begin{array}{cc}20.8 & h \\
6.7 & h \\
5.27 & d\end{array}$ & $\begin{array}{l}6.9 \\
6.1 \\
0\end{array}$ & $\begin{array}{l}9.25 \times 10^{-6} \\
2.87 \times 10^{-5} \\
1.52 \times 10^{-6}\end{array}$ & - \\
\hline $\mathrm{Xe}-135$ & $9.2 \mathrm{~h}$ & $\approx 0$ & $2.09 \times 10^{-5}$ & $2.7 \times 10^{6}$ \\
\hline $\mathrm{Kr}-88$ & $2.8 \mathrm{~h}$ & $3.57 ?$ & $6.87 \times 10^{-5}$ & - \\
\hline
\end{tabular}

Purification Constants

For Ion Exchange or Leakage $k_{p}=\frac{F_{I X}}{V_{T} \times 60}$

whẹre

$$
\begin{aligned}
& F_{I X}=\text { ion exchange or leak flow rate, gpm } \\
& V_{T}=\text { total coblant volume, gallons }
\end{aligned}
$$

At Saxton,

$$
\mathrm{k}_{\mathrm{p}}=\frac{\mathrm{F}_{\mathrm{IX}}}{2400 \text { gal } \times \text { hก s/m }}=7 \times 10^{-6} \mathrm{~F}_{\mathrm{IX}} \text { sar }^{-1}
$$

* For Gaseous Leakage (100\% from pressurizer) $\mathrm{k}_{1}=\frac{\mathrm{F}_{\mathrm{p}}}{\mathrm{V}_{\mathrm{T}} \mathrm{x} \cdot 60}$

$$
\text { where } \quad \begin{aligned}
& \mathrm{F}_{\mathrm{p}}=\text { spray-line flow to pressurizer. gpm } \\
& \mathrm{V}_{\mathrm{T}}=\text { total coolant volume, gallons }
\end{aligned}
$$

At Saxton,

$$
\mathrm{k}_{1}=\frac{\approx 0.2}{2400 \times 60}=1.4 \times 10^{-6} \mathrm{sec}^{-1}
$$

* Since abnut Augunt, 1963, a sizeable gaseous leak from the main coolant has been measured at Saxton, and $i t$ is assumed, herein, that gases carried to the pressurizer via the spray line will leak from the system. 
where $A_{A}^{C}=$ nuclide activity, $\mathrm{dpm} / \mathrm{ml}$ coolant

$$
\begin{aligned}
\therefore \quad V_{T} & =\text { total coolant volume, } m \\
& =9.1 \times 10^{6} \mathrm{ml} \text { at Saxton } \\
& =N_{A}^{C}=\frac{A}{\lambda_{A}^{C}}\left(1.52 \times 10^{5}\right)
\end{aligned}
$$

c. $k_{p}$, purification or leakage constant,

During the period of sampling, re. Figure 9, of August 15 to September 25 ( 41 days) the total makeup for leakage was about 1815 gallons, for an average of 44 gal/day. Thus,

$$
\begin{aligned}
k_{p} & =\frac{44 \mathrm{gpa} \times 3.785 \mathrm{ml} / \mathrm{gal}}{9.1 \times 10^{6} \mathrm{ml} \times 8.64 \times 10^{4} \mathrm{~s} / \mathrm{d}} \\
& =2.12 \times 10^{-10} \mathrm{sec}^{-1}
\end{aligned}
$$

This value, compared to the decay constants of any of the iodine isotopes of interest, is negligible and may be omitted, therefore, in the computation of 8 of Eqn. (9).

With the above substitutions, $\beta$ is reduced to

$$
\beta=\frac{A_{A}^{C}}{P_{t} Y_{A}}\left(4.04 \times 10^{-3}\right)
$$

Using this value for $B$, Eqn. (9) was solved for $\nu_{A}$ for each value of $1^{131}, I^{133}$, and $I^{135}$ and these are given in Table 3 .

Some additional samples of coolant were collected to obtain the concentration of fissinn product yuses resulting from the defect. The techniques used to collect and analyze the samples are given in Appendix B. The data obtained is given in Table 8, showing 
TABLE 8

Fission Product Gases in Saxton Coolant

a. $\mathrm{Xe}$

\begin{tabular}{|c|c|c|c|c|c|}
\hline \multirow{2}{*}{$\begin{array}{c}\text { Sample. } \\
\text { Date/Time }\end{array}$} & \multicolumn{2}{|c|}{ Coolant Activity, dpm/cc } & \multirow{2}{*}{$\begin{array}{c}\nu \text { of } \mathrm{I}^{133} \\
\mathrm{sec}^{-1}\end{array}$} & \multirow{2}{*}{$\begin{array}{l}v \text { of } \mathrm{Xe}^{133} \\
\mathrm{sec}^{-1}\end{array}$} & \multirow{2}{*}{ Remarks } \\
\hline & $x e^{133}$ & $I^{133}$ & & & \\
\hline $8-18-64 / 0755$ & $4.89 \times 10^{4}$ & $4.10 \times 10^{5}$ & - & & 20 MWt power \\
\hline $9-23-64 / 1715$ & $2.34 \times 10^{6}$ & $6.68 \times 10^{4}$ & $1.54 \times 10^{-9}$ & $1.57 \times 10^{-8}$ & 23.5 MWt power \\
\hline $9-24-64 / 0900$ & $3.14 \times 10^{0}$ & $9.66 \times 10^{4}$ & $2.22 \times 10^{-9}$ & $2.29 \times 10^{-8}$ & 23.5 MWt power \\
\hline $9-24-64 / 1719$ & $1.95 \times 10^{6}$ & $1.23 \times 10^{4}$ & $2.22 \times 10^{-9}$ & $1.15 \times 10^{-8}$ & $\left\{\begin{array}{l}\text { After } 1.92 \text { system vols. } \\
\text { through IX purification }\end{array}\right.$ \\
\hline $9-25-64 / 0835$ & $2.44 \times 10^{6}$ & $5.05 \times 10^{4}$ & $2.22 \times 10^{-9 *}$ & $3.43 \times 10^{-8}$ & $\left\{\begin{array}{l}10.4 \text { hours after end of } \\
\text { IX purification }\end{array}\right.$ \\
\hline
\end{tabular}

b. $\mathrm{xe}^{135}$

\begin{tabular}{|c|c|c|c|c|c|}
\hline \multirow{2}{*}{$\begin{array}{c}\text { Sample } \\
\text { Date/Time }\end{array}$} & \multicolumn{2}{|c|}{ Coolant Activity, dpm/cc } & \multirow{2}{*}{$\begin{array}{c}\nu \text { of } I^{135} \\
\sec ^{-1}\end{array}$} & \multirow{2}{*}{$\begin{array}{c}\nu \text { of } \mathrm{Xe}^{135} \\
\sec ^{-1}\end{array}$} & \multirow{2}{*}{ Remarks } \\
\hline & $\mathrm{Xe}^{135}$ & $I^{135}$ & & & \\
\hline $8-18-64 / 0755$ & $5.23^{\prime} \times 10^{4}$ & $1.33 \times 10^{5}$ & 1 & 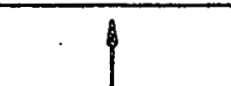 & \multirow{5}{*}{ (See Above) } \\
\hline $9-23-64 / 1715$ & $3.99 \times 10^{5}$ & - & & & \\
\hline $9-24-64 / 0900$ & $4.77 \times 10^{5}$ & - & inot & Not & \\
\hline $9-24-64 / 1719$ & $1.33 \times 10^{5}$ & - & Calcd. & Calcd. & \\
\hline $9-25-64 / 0835$ & $1.43 \times 10^{5}$ & - & 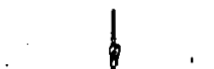 & $\therefore \quad 1$ & \\
\hline
\end{tabular}

\begin{tabular}{|c|c|c|c|}
\hline $\begin{array}{c}\text { Sample } \\
\text { Date/Time }\end{array}$ & $\mathrm{Kr}^{88}$ Activity & $\begin{array}{c}\text { Reactor } \\
\text { Power } \\
\text { MWt. }\end{array}$ & $\begin{array}{c}\text { vof } \mathrm{Kr}_{r}^{88} \\
\mathrm{sec}^{-1}\end{array}$ \\
\hline $9-23-64 / 1600$ & $5.70 \times 10^{4}$ & 23.5 & $1.92 \times 10^{-8}$ \\
$9-24-64 / 0840$ & $12.7 \times 10^{4}$ & 23.5 & $4.26 \times 10^{-8}$ \\
\hline
\end{tabular}

* Assuming $4.26 \times 10^{-9}$ best value for $\nu$ of $I^{133}$ from previous data. 
activity concentrations for $\mathrm{Xe}^{133}, \mathrm{Xe}^{135}$, and $\mathrm{Kr}^{88}$. For $\mathrm{Xe}^{133}$, the escape rate coefficients were computed from Eqn. (13), using the observed data for parent $I^{133}$. No escape coefficients were computed for $\mathrm{Xe}^{135}$ since the data obtained for concurrent $I^{135}$ are too meager and uncertain. The escape rate coefficient for parent $\mathrm{Kr}^{88}$ was computed using Egn. (9) with constants relating to defect power used previously, above.

Radiochemical analyses of the primary coolant and purification demineralizer effluent during one day of purification are presented in Table 4. From this data, the demineralizer efficiency was computed for fission products iodine and cesium, and tramp sodium. During this period of demineralizer purification, the flow rate was maintained at $11.5 \mathrm{gpm}$. The demineralizer consisted of 6 cu. ft. of Iilco NR-9, mixed-bed resin, regenerated in the potassium-borate forms. At $11.5 \mathrm{gpm}$ flow rate, the crosssectional flow is $3.7 \mathrm{gpm} / \mathrm{ft}^{2}$ and the bed depth is nominally $2 \mathrm{ft}$.

Decontamination factors for nuclides (IX inlet activity/ IX outlet activity) are given in Table 4, where data was collected. In many instances, the outlet activity of a particular nuclide was at or below the limit of detection, and for these a minimum D.F. is tabulated assuming a detection limit of $100 \mathrm{dpm} / \mathrm{cc}$, in effluent samples.

The data for $I^{131}$ and $I^{133}$ activities in the coolant, which represent ion exchange inlet samples in Table 4, may be analyzed as a function of time to further support the mechanism of fission 
product release from the defected fuel rod. As given earlier, the change in nuclide inventory in the coolant is expressed by,

$$
\frac{d N_{A}^{c}}{d t}=N_{A}^{f} \nu_{A}-N_{A}^{c} \lambda_{A}-N_{A}^{c} k_{p}
$$

which may be rearranged and integrated between limits of $t_{0}$ for $\mathrm{N}_{\mathrm{Ao}}^{\mathrm{C}}$ and to for $\mathrm{N}_{\mathrm{A}}^{\mathrm{C}}$. The result is,

$$
\frac{N_{A}^{C}}{N_{A O}^{c}}=\frac{N_{A}^{f} \nu_{A}}{N_{A o}^{c} \beta}+e^{-\beta t} \cdot\left(1-\frac{N_{A}^{f} \nu_{A}}{N_{A o}^{c} \beta}\right)
$$

where $\beta=\left(\lambda_{A}+k_{p}\right)$

This equation may be simplified further by noting that at steady state, at the time of start of demineralization, $\mathbb{N}_{A}^{f} \nu_{A}=$ $\mathrm{NN}_{\mathrm{A} \rho}^{\mathrm{C}} \lambda_{\mathrm{A}}$. Thus,

$$
\frac{N^{C}}{N_{0}^{C}}=\frac{\lambda}{\beta}+e^{-\beta t}\left(1-\frac{\lambda}{\beta}\right)
$$

Parameters used during the period of ion exchange purification were substituted into the equation to obtain the theoretical variation of $I^{131}$ and. $I^{133}$ with time. This is shown in Figure 10, together with the observed data for these two nuclides. For these calculations, the demineralizer efficiency to remove the iodine nuclides was taken to be 100 percent. Also shown in Figure 10 is the time variation in concentration due to ion exchange of a hypothetical substance with no decay and without a continuous source to the coolant, included for comparison. 


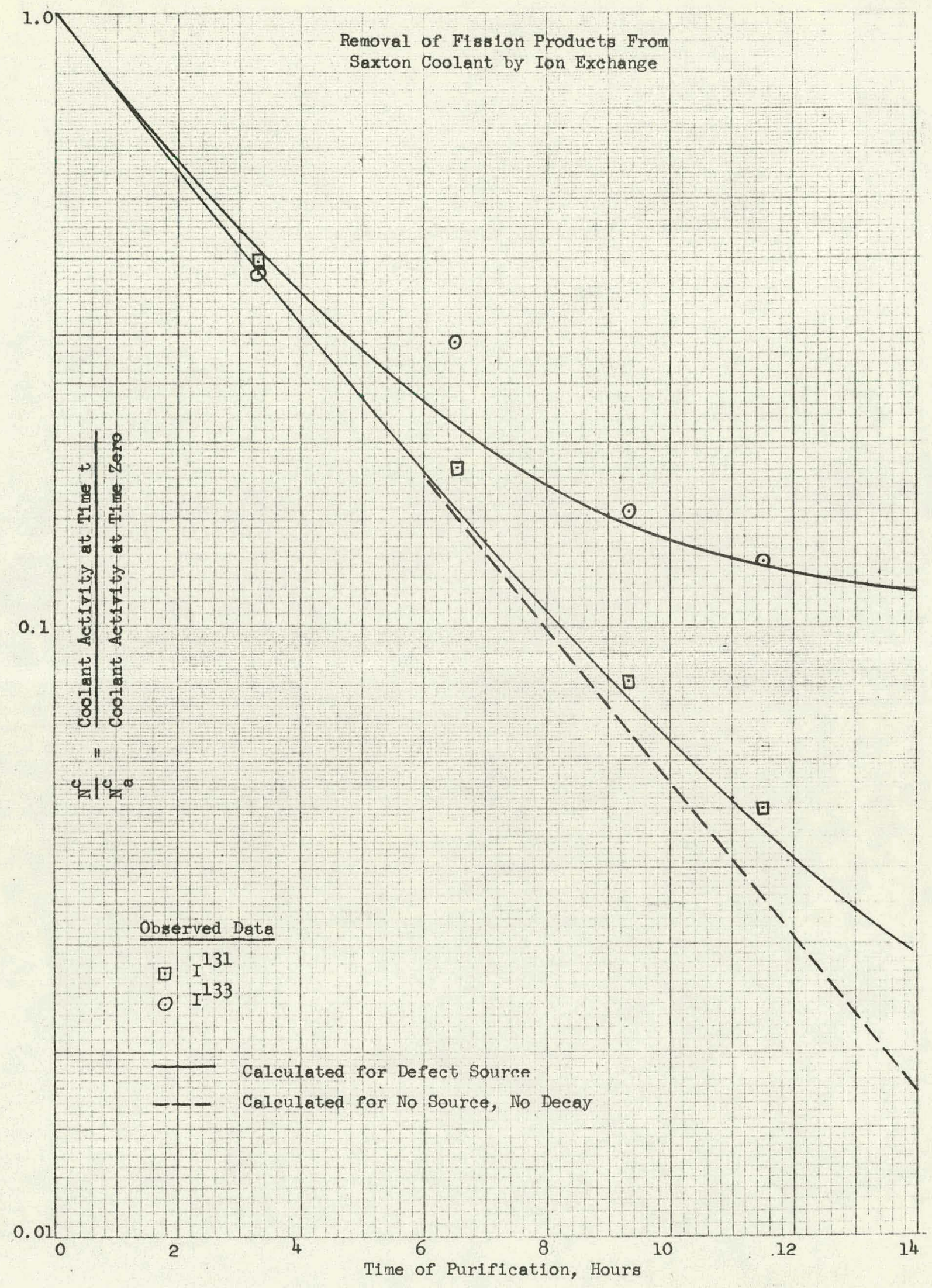

Figure 10 
VII. DISCUSSION OF RESULTS

The mathematical model for the escape of fission products from a defected fuel rod, presented in Section $V$, is considered valid and applicable to the analysis iof data from pressurized water reactors. The model does use an escape rate coefficient, $\nu$, as a general parameter, and assumes this to be constant regardless of defect position in the fuel rod cladding, or regardless of the fuel temperature or location in the core. With only one known defect in the core, the conditions which might affect $\nu$ were fixed, and since these conditions were the most severe that could be obtained at Saxton, the calculated V's are conservatively higher. than might be obtained from a core-average defect.

The value of $\nu$ for fission product iodines is best ascertained from the last two days of sampling (re. Table 3), for which period the coolant activity was nearest to steady state. The average $V$ 's are:

$$
\begin{array}{ll}
I-131(8.05 \mathrm{~d}) & \nu=2.20 \times 10^{-9} \mathrm{sec}^{-1} \\
I-133_{\mathrm{a}}(20.8 \mathrm{~h}) & \nu=1.62 \times 10^{-9} \mathrm{sec}^{-1}
\end{array}
$$

Owing to the short half life of $I-133$ and I-135, other data from Table 3 may be selected to obtain an average $\nu$ for periods after the reactor had operated steadily, i.e., where these nuclide activities would be near steady-state. Figure 9 indicates that data of $8-18,8-27$ and $8-28$ would be near steady-state, for which average $\nu^{\prime}$ s are:

$$
\begin{array}{ll}
I-133_{\mathrm{b}} \cdot(20.8 \mathrm{~h}) & v=6.2 \times 10^{-9} \mathrm{sec}^{-1} \\
I-135(6.7 \mathrm{~h}) & v=13.9 \times 10^{-9} \mathrm{sec}^{-1}
\end{array}
$$

These data indicate a variation in $\nu$ between the same nuclides of different half-lives. This is, a priori, surprising, considering the chemical and phyaical sensilivity of isotopes, however it can be shown $\frac{2,3}{2}$ 
that the escape rate coefficient is related to the diffusion coefficient as follows:

$$
\nu=3 D \sqrt{\lambda}
$$

where $D\left(\sec ^{-\frac{1}{2}}\right)$ is a modified mean diffusion coefficient for the nuclide in $\mathrm{UO}_{2}$. This relation results from the assumption that the escape is controlled by diffusion in the fuel pellet and shows that the resulting $\nu$ will be directly proportional to $\sqrt{\lambda}$. Average data for $\nu$, given above, can be compared for consistency after being normalized by a divisor of $\sqrt{\lambda}$, as follows:

\begin{tabular}{|c|c|c|c|}
\hline Nuclide & Apparent $v, \mathrm{sec}^{-1}$ & $\lambda, \sec$ & $\nu / \sqrt{\lambda}$ \\
\hline I-13I & $2.20 \times 10^{-9}$ & $9.96 \times 10^{-7}$ & $2.2 \times 10^{-}$ \\
\hline$I-133 a$ & $1.62 \times 10^{-9}$ & $9.25 \times 10^{-6}$ & $0.52 \times 10^{-}$ \\
\hline$I-133 b$ & $6.2 \times 10^{-9}$ & $9.25 \times 10^{-6}$ & $2.0 \times 10^{-}$ \\
\hline$[-135$ & $13.9 \times 10^{-9}$ & $2.87 \times 10^{-5}$ & $2.6 \times 10^{-}$ \\
\hline
\end{tabular}

The result shows that escape rate coefficients, of the same element at least, are consistent when compared on the basis of diffusion coefficients. This agrees with the thesis of Frank, Allison, and others where in the release of fission products to the reactor coolant via a dofect is controlled in large measure by diffusion in the fuel.

A similar appraisal of the apparent escape rate coefticients for fission gases may be made, as above. Table 8 gives the calculated values of $\nu$ for $\mathrm{Xe}-133$ and $\mathrm{Kr}-88$. The averaged values for these $\nu^{\top} \mathrm{s}$, considering that all data represent the steady-state condition, are:
$\frac{\text { Nuclide }}{\text { Xe-133. }}$
$\frac{\text { Apparent } v, \mathrm{sec}^{-1}}{\text { - }}$
$\frac{\lambda, \sec ^{-1}}{.52 \times 10^{-6}}$
$\nu / \lambda \sqrt{\lambda}$
$\mathrm{Kr}-88$

$$
3.09 \times 10^{-8}
$$
$6.87 \times 10^{-5}$
$17.5 \times 10^{-6}$
$3.8 \times 10^{-6}$ 
While the normalized $\nu$ for $\mathrm{Kr}-88$ is in reasonable agreement with the values computed for the iodines, the Xe-133 is significantly different. There is no apparent reason to explain the discrepancy, although one would not necessarily expect the behavior of iodines and fission gases to be the same. If the rate'controlling step for the release of fission products from a defect is diffusion in the fuel pellet, as pointed out by Allison and Frank, a difference in the release of halogens versus rare gases would not be altogether unexpected. However, since the difference in normalized $V^{\prime}$ ' for $\mathrm{Xe}$ and $\mathrm{Kr}$ is significant, one may speculate that this results from the mode of calculation, wherein $\mathrm{Kr}$ is treated as a primary product of fission, while the $\nu$ of $\mathrm{Xe}$ is computed with reference to the parent I-133 coolant activity and escape rate coefficient.

It is of interest that escape rate coefficients for gaseous fission products $\mathrm{Xe}$ and $\mathrm{Kr}$ were measured to be higher by a factor of 10 than the iodine nuclides. This is somewhat different than has been reported by other investigators, such as Frank $\angle 4$ in early studies at BAPI, who reported that $\mathrm{Cs}, \mathrm{I}, \mathrm{Xe}, \mathrm{Kr}, \mathrm{Rb}$, and $\mathrm{Br}$ each have an escape rate coefficient of $1.3 \times 10^{-8}$ $\sec ^{-1}$. Some of his data, however, would indicate the coefficient for gases to be a factor of 10 higher than the iodines. Subsequent work by Frank $\frac{22}{2}$ with a defected $\mathrm{UO}_{2}$ fuel rod indicates the escape rate coefficient of $\mathrm{Xe}-133$ and $\mathrm{Xe}-135$ is nearly the same as I-13I and I-133, while that of the kryptons is higher than that of the iodines by a factor of 5 to 35 .

As pointed out above, the apparent escape rate coefficient for an element w1li vary with the half-life of the particular nuclide. Moreover, Allison and Rae have shown recently that fuel element length, as well as fuel 
temperature, $\mathrm{UO}_{2}$ crystallite size and density, will significantly alter the coefficient value. Needless to say; in view of the large number of variables which may affect the escape rate of fission products from a defect, the extrapolation of this and other published data to predict releases from plants yet to be operated is tenuous, at best. Nonetheless, for $\mathrm{UO}_{2}$ fuel rods which will operate at power ratings no higher than this particular defect assembly. (13.5 kw/ft), and are similar dimensionally ( $\mathrm{re}$. Table l), the escape rate coefficients calculated herein are believed adequate.

One additional consideration should be made with regard to the calculated, apparent escape rate coefficients. It is entirely possible that the intentional defect was accompanied by other defects in the reactor core. The Saxton core has indicated the presence of other defects during operation prior to this defect test. Whether or not the unknown defect was with the assembly removed to make way for the defect assembly is not known. Should there have been an additional defect somewhere in the core during this test, the values for $\nu$ would be conservatively high - the proper direction for design purposes. The data presented in Table 4, on which Figure 10 was based, indicates good agreement between theory and observation for the apparent transport of fission products from a defect. There is a marked difference between system clean-up of a substance that is not continually fed to the coolant and cleanup of fission products arising from the defect.

The decontaminalion factors given in Table 4 for various nuclides are very much ac cxpected. All nuclides were efficiently removed from the coolant. with the exception of cesium. Th1s element is not favorably exchanged by potassium-form ion exchange resins. In other cases, cesium is efficiently removed hy hydrogen-or lithium-form resins. 


\section{CONCLUSIONS}

The defect test in the Saxton Reactor has been completed with a number of important results. In retrospect, a much longer operating time with the defect in-core would have been preferred. However, the data obtained has permitted estimates of escape rate coefficients of the halogen and rare gas fission products. Heretofore, design calculations have used very conservative escape rate coefficients for these Pission products ( $1.3 \times 10^{-8} \mathrm{sec}^{-1}$ for iodines and $6.5 \times 10^{-8} \mathrm{sec}^{-1}$ for gases) but the results of this test indicate the magnitude to be a factor of up to io for iodine. A summary of the escape rate coefficients averaged from data. collected during this test is as follows:

\begin{tabular}{|c|c|}
\hline Nuclide & $\underline{v}, \sec ^{-1}$ \\
\hline$I-131$ & $2 \times 10^{-9}$ \\
\hline I-133 & $8 \times 10^{-9}$ \\
\hline I-135 & $14 \times 10^{-9}$ \\
\hline $\mathrm{Xe}-133$ & $20 \times 10^{-9}$ \\
\hline $\mathrm{Kr}-88$ & $30 \times 10^{-9}$ \\
\hline
\end{tabular}

These values may be used for design purposes so long as it is assumed that a reactor core will have operating characteristics (fuel power rating) and physical dimensions (fuel composition, fuel rod length, etc.) similar to those of this defect rod. 


\section{APPENDICES}

A-1 Radiochemical Analysis of Solutions
A-2 Separation and Analysis of Fission Gases from Solution 


\section{APPENDIX A-1}

\section{RADIOCHEMICAL ANALYSIS OF 'SOLUTION SAMPLES}

Samples of the Saxton primary coolant were collected at a sample line leading directly from the primary loop. The sample stream was cooled from $\approx 530^{\circ} \mathrm{F}$ to $\approx 80^{\circ} \mathrm{F}$ and after sufficient purge time to cleanse the line, a batch sample was collected in a new, clean, polyethylene bottle. Aliquots of this sample were analyzed for iodine and cesium fission products after a delay of at least 10 hours. Individual analyses were performed as follows:

Iodine: to separate iodine activities from other fission and corrosion product activities in the sample, the usual, repetitive oxidationreduction reaction with iodine carrier was performed, with a final extract of iodine into an aqueous layer from $\mathrm{CCl}_{4} \cdot \frac{\angle 5}{}$ The iodine was precipitated with acidified $\mathrm{AgNO}_{3}$, and the $\mathrm{AgI}$ precipitate filtered, and mounted for analysis by gamma spectrometry.

The composite gamma-spectrum of I-131, I-133, and I-135 was analyzed by graphical-stripping methods $\frac{16}{}$ and contirmed by allowing the sample to decay and recounting. All activities are corrected for decay to the time of sampling.

Cesium: in, some sanplea, activities other than cesium were low due to long decay times, in which case, $\mathrm{Cs}^{137}$ and $\mathrm{Cs}^{134}$ were determined by direct $\gamma$-counting of a sample aliquot. The $0.662 \mathrm{Mev}$ peak of $\mathrm{Cs}{ }^{137}$ and the 0.601 and $0.796 \mathrm{Mev}$ peaks of $\mathrm{Cs}^{134}$ were resolved by graphical methods combined with algebraic computation. The method of peak resolution is easily standardized through use of standard, pure $\mathrm{Cs}^{137}$ and $\mathrm{Cs}^{134}$ isotope mixtures. 
For samples which contained significant quantities of other nuclides, cesium was separated from solution by the tetraphenyl boron extraction method, $\angle 7$ and the resulting extract $\gamma$-counted and analyzed as above. Sodium: although not a fission product, $\mathrm{Na}^{24}$ was detected in the reactor coolant (from trace $\mathrm{Na}$ contamination) and analyzed by direct $y$-counting a sample aliquot. The quantity of $\mathrm{Na}^{24}$ was determined from the gamma spectrum, by integrating the area of the $2.74 \mathrm{Mev}$ peak. 


\section{APPENDIX A-2}

SEPARATION AND ANALYSIS OF FISSION GASES FROM SOLUTION

Primary coolant samples for gas stripping and analysis were collected in stainless steel, valve-ended vessels, of about $50 \mathrm{ml}$ volume. The coolant sample stream was allowed to flow from the reactor system through the sample vessel without cooling. After purging the line and sample vessel for at least 10 minutes at $\approx 0.6 \mathrm{gpm}$, the downstream vessel valve was slowly closed, then the upstream vessel valve was closed, thus isolating the liquid/gas sample. The sample vessel was removed to the laboratory while still hot $\left(>60^{\circ} \mathrm{C}\right.$ ) and connected to an evacuated, glass bulb having a volume of $\approx 60 \mathrm{ml}$ : The valve between vessel and bulb was carefully opened, followed by slight opening of the other vessel valve, thus sweeping dissolved gases from the vessel to the bulb. Aliquots of the gas in the bulb were removed by hypodermic syringe and transferred to small ( $3 \mathrm{ml}$ ), evacuated, counting vials. These vials were then $\gamma$-counted using a $2 \times 2$ well crystal and 400 channel spectrometer. The spectrum of Xe-133 and Xe-135 was resolved by graphical stripping methods $\angle 6$ confirmed by decay studies.

For $\mathrm{Kr}-88$, use was made of the B-activity of the Rb-88 daughter. For this, a gas aliquot was removed from the bulb, described above, and introduced into an evacuated counting vial containing $1.0 \mathrm{ml}$ of $2 \mathrm{M}^{\mathrm{HNO}_{3}}$. After standing for one holu, to permil equilibrium between $\mathrm{Kr}-88$ and $\mathrm{Rp}-88$, the vial was vigorously shaken, opcned, and an aliquot of the nitric acid was removed, dried on a planchet, and B-counted. The amount of $\mathrm{Kr}-88$ in the coolant sample was then calculated from the assay of $\mathrm{Rb}-88$ on the planchet. 
1. WCAP-3269-43, "Performance of Zircaloy Fuel Rods in Saxton", D. R. McClintock (to 'be published).

2. WAPD-BT-12, "One Year of Operating Experience at Shippingport", p. 118 ff., P. W. Frank, April 1959.

3. RLI-4, "The Behavior of Fission Products in Pressurized Water Systems", G. M. Allison and R. F. S. Robertson, February 1961.

4. WAPD-TM-29, "Radiochemistry of Third PWR Fuel Material Test, X-I Loop Reactor", P. W. Frank, K. H. Vogel, and P. Cohen, February 1, 1957.

5. NAS-NS-3005, "The Radiochemistry of Fluorine, Chlorine, Bromine, and Iodine", J. Kleinberg and G. A. Cowan, Procedure 15, p. 31, January 1960.

6. L. C. Bogar and C. J. L. Lock, "Radiochemical Analysis of Corrosion Product Mixtures from High Temperature Pressurized Water Loop Systems", Talanta 6, 133-143, (1960).

7. NAS-NS-3035, "The Radiochemistry of Cesium", H. L. Finston and M. T. Kinsley, Procedure 8, p. 50, February 1961. 